\title{
Munc18-1 Is Essential for Neuropeptide Secretion in Neurons
}

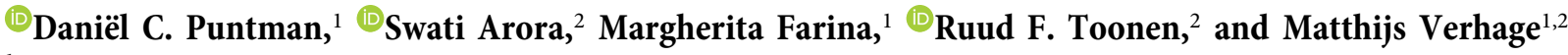 \\ ${ }^{1}$ Section Functional genomics, Department of Clinical Genetics, Center for Neurogenomics and Cognitive Research, Universitair Medisch Centrum, \\ Amsterdam1081 HV, The Netherlands, and ${ }^{2}$ Department of Functional Genomics, Center for Neurogenomics and Cognitive Research, Vrije \\ Universiteit Amsterdam, Amsterdam1081 HV, The Netherlands
}

Neuropeptide secretion from dense-core vesicles (DCVs) controls many brain functions. Several components of the DCV exocytosis machinery have recently been identified, but the participation of a SEC1/MUNC18 (SM) protein has remained elusive. Here, we tested the ability of the three exocytic SM proteins expressed in the mammalian brain, MUNC18-1/2/3, to support neuropeptide secretion. We quantified DCV exocytosis at a single vesicle resolution on action potential (AP) train-stimulation in mouse CNS neurons (of unknown sex) using pHluorin-tagged and/or mCherry-tagged neuropeptide Y (NPY) or brainderived neurotrophic factor (BDNF). Conditional inactivation of Munc18-1 abolished all DCV exocytosis. Expression of MUNC18-1, but not MUNC18-2 or MUNC18-3, supported DCV exocytosis in Munc18-1 null neurons. Heterozygous (HZ) inactivation of Munc18-1, as a model for reduced MUNC18-1 expression, impaired DCV exocytosis, especially during the initial phase of train-stimulation, when the release was maximal. These data show that neurons critically and selectively depend on MUNC18-1 for neuropeptide secretion. Impaired neuropeptide secretion may explain aspects of the behavioral and neurodevelopmental phenotypes that were observed in Munc18-1 HZ mice.

Key words: Munc18-1; dense-core vesicle; neuropeptide

Significance Statement

Neuropeptide secretion from dense-core vesicles (DCVs) modulates synaptic transmission, sleep, appetite, cognition and mood. However, the mechanisms of DCV exocytosis are poorly characterized. Here, we identify MUNC18-1 as an essential component for neuropeptide secretion from DCVs. Paralogs MUNC18-2 or MUNC18-3 cannot compensate for MUNC18-1. MUNC18-1 is the first protein identified to be essential for both neuropeptide secretion and synaptic transmission. In heterozygous (HZ) Munc18-1 neurons, that have a 50\% reduced MUNC18-1expression and model the human STXBP1 syndrome, DCV exocytosis is impaired, especially during the initial phase of train-stimulation, when the release is maximal. These data show that MUNC18-1 is essential for neuropeptide secretion and that impaired neuropeptide secretion on reduced MUNC18lexpression may contribute to the symptoms of STXBP1 syndrome.

\section{Introduction}

Neuropeptides control diverse brain functions such as memory, appetite, and mood (Cropper et al., 2018; Comeras et al., 2019;

\footnotetext{
Received Dec. 16, 2020; revised Apr. 29, 2021; accepted May 3, 2021.

Author contributions: D.C.P., S.A., M.F., R.F.T., and M.V. designed research; D.C.P., S.A., and M.F. performed research; S.A. and M.F. analyzed data; D.C.P., R.F.T., and M.V. wrote the paper.

This work was supported by the ERC Advanced Grant 322966 of the European Union (to M.V.). We thank RobbertZalm for cloning and producing viral particles, Lisa Laan and Desiree Schut for producing glia island cultures and providing primary culture assistance, Joke Wortel for organizing the animal breeding, Joost Hoetjes for genotyping, JurjenBroeke for technical support, Ingrid Saarloos for Western blottings, and members of the Center for Neurogenomics and Cognitive Research DCV team for discussions and helpful input.

The authors declare no competing financial interests.

Correspondence should be addressed to Matthijs Verhage at matthijs@cncr.vu.nl or Ruud F. Toonen at ruud.toonen@cncr.vu.nl.

https://doi.org/10.1523/JNEUROSC1.3150-20.2021

Copyright $\odot 2021$ the authors
}

Miranda et al., 2019), but the mechanisms that drive neuropeptide release from dense-core vesicles (DCVs) remain poorly understood. The principles of secretory vesicle exocytosis are well conserved and first characterized in yeast (Novick and Schekman, 1979; Novick et al., 1980, 1981; Aalto et al., 1993; Protopopov et al., 1993). Four canonical components appear to be essential in all types of regulated exocytosis: three SNARE proteins, of the (1) SNAP/SEC9 family; (2) the synaptobrevin/VAMP/SNC family; and (3) the syntaxin/SSO1/2 family; and (4) a SEC1/MUNC18 (SM) protein (Toonen and Verhage, 2003, 2007; Jahn and Scheller, 2006; Südhof and Rothman, 2009; Südhof, 2013; Kaeser and Regehr, 2014). While two of these canonical components have recently been identified for DCV exocytosis in mammalian neurons (Shimojo et al., 2015; Arora et al., 2017; Hoogstraaten et al., 2020), the participation of an SM protein has remained elusive. 
Table 1. Statistical analysis summary and experimental design

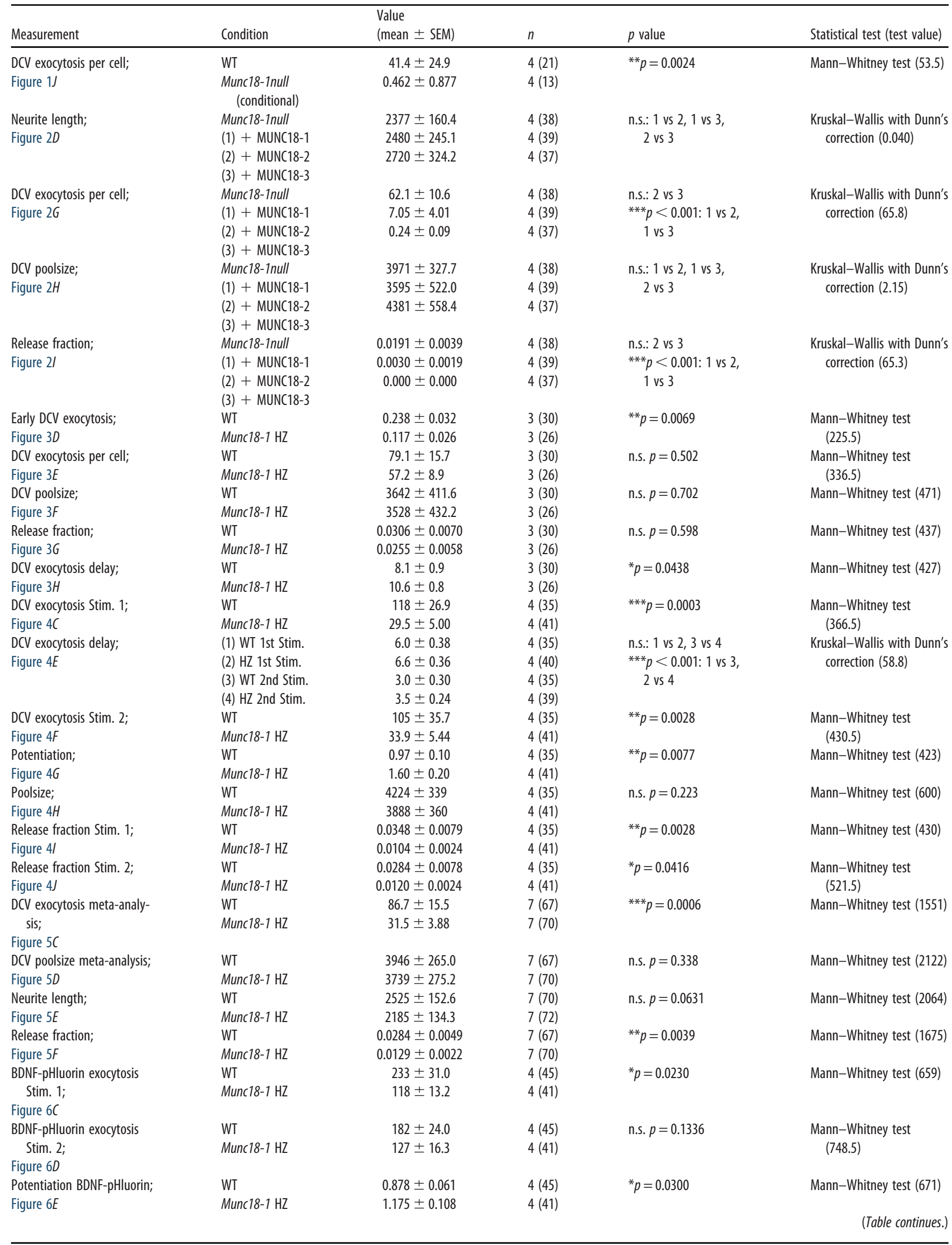


Table 1. Continued

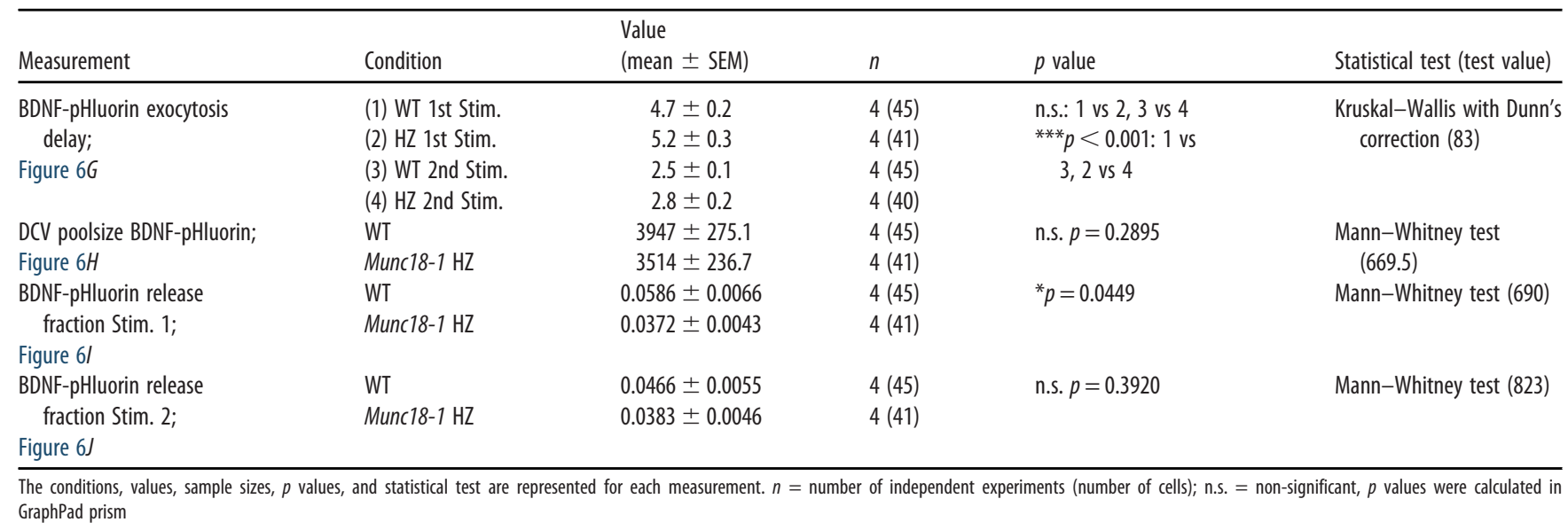

In mammals, seven $\mathrm{SM}$ proteins are expressed: mSly1, mVPS33A, mVPS33B, mVPS45, MUNC18-1, MUNC18-2, and MUNC18-3. The first four control internal membrane trafficking, while the three MUNC18 proteins control exocytosis (for a review, see Toonen and Verhage, 2003). MUNC18 proteins bind syntaxins(Thurmond et al., 1998; Misura et al., 2000; Kauppi et al., 2002; Dulubova et al., 2007; Burkhardt et al., 2008; Bin et al., 2013), promote docking of secretory vesicles (Voets et al., 2001; de Wit et al., 2009) and probably serve as a template for SNAREcomplex assembly, which drives exocytosis (Parisotto et al., 2014; Sitarska et al., 2017; Jiao et al., 2018; Meijer et al., 2018; Wang et al., 2019; André et al., 2020). MUNC18-2 acts in blood platelets, cytotoxic T lymphocytes, natural killer cells and mast cells (Côte et al., 2009; Hackmann et al., 2013; Gutierrez et al., 2018; Cardenas et al., 2019); MUNC18-3 in adipocytes (Tamori et al., 1998; Thurmond et al., 2000); and MUNC18-1 in chromaffin cells and the posterior pituitary (Voets et al., 2001; Korteweg et al., 2005) and in synaptic vesicle (SV) exocytosis in neurons (Verhage et al., 2000). In other cell types, such as lung mucus cells and pancreatic $\beta$-cells, multiple MUNC18 paralogs support different phases of secretion in the same pathway (Oh and Thurmond, 2009; Oh et al., 2012; Lam et al., 2013; Jaramillo et al., 2019). In neurons, all three MUNC18 paralogs are expressed, but MUNC18-1 has a 10-fold higher expression and is the only paralog that supports neurotransmission (Verhage et al., 2000; Yue et al., 2014; Zeisel et al., 2015; He et al., 2017; Santos et al., 2017). Which SM-protein(s) support DCV exocytosis is unknown.

To identify which SM protein(s) support DCV exocytosis in neurons, we analyzed DCV fusion with single vesicle resolution using three fluorescent DCV-fusion reporters in primary neurons from homozygous and heterozygous (HZ) Munc18-1 null mutant mice. We found that Munc18-1 inactivation abolished neuropeptide release and that expression of MUNC18-2 or MUNC18-3 did not restore DCV exocytosis. HZ Munc18-1 inactivation reduced DCV exocytosis. We conclude that neurons critically and specifically depend on MUNC18-1 for neuropeptide secretion.

\section{Materials and Methods}

\section{Animals}

Animal housing and breeding was in line with institutional and Dutch governmental guidelines and all procedures were approved by the ethical committee of the Vrije Universiteit University/Vrije Universiteit Medical Center (license number: DEC-FGA 11-03 and AVD112002017824).
Munc18-1 ${ }^{\text {lox/lox }}$ mice (Heeroma et al., 2004) and Munc18-1 null mice [Munc18-1 knock-out (KO); Verhage et al., 2000; Toonen et al., 2006b] were generated as described before. To obtain Munc18-1 conditional KO (cKO) primary cultures, Munc18-1 $1^{\text {lox/lox }}$ mice were time-mated and P1 pups were used for dissection of the hippocampi. For Munc18-1 wildtype (WT), Munc18-1 KO, and Munc18-1 HZ primary cultures, Munc18-1 HZ mice were time-mated and embryonic day (E)18 pups were collected via caesarean section, after which they were used for dissection of the hippocampi. All pups were genotyped before culturing and were of unknown sex.

\section{Neuron culture}

Preparation of dissociated hippocampal neuron cultures was performed as reported before (De Wit et al., 2009; Farina et al., 2015). In brief, isolated hippocampi were digested with $0.25 \%$ trypsin (Life Technologies) for $20 \mathrm{~min}$ at $37^{\circ} \mathrm{C}$ in HBSS (Sigma) with $10 \mathrm{~mm}$ HEPES (Life Technologies). After $3 \times$ washing and trituration, 1000-2000 neurons were plated per well onto pregrown glia microislands. These were generated by stamping agarose coated $18 \mathrm{~mm}$ glass coverslips with a solution of $0.5 \mathrm{mg} / \mathrm{ml}$ poly-D-lysine (Sigma), $3.5 \mathrm{mg} / \mathrm{ml}$ rat tail collagen (BD Biosciences), and $17 \mathrm{~mm}$ acetic acid onto which 6.000 rat glia were plated (Mennerick et al., 1995; Wierda et al., 2007).

\section{Viruses}

All constructs were generated with sequence verification, cloned into a pLenti vector containing a Synapsin promotor. To obtain Munc18-1 cKO and control neurons, Cre recombinase and defective Cre (deltaCre; Kaeser et al., 2011; Persoon et al., 2019) were delivered into Munc18-1 $1^{\text {lox/lox }}$ neurons via lenti-virus particles at day in vitro (DIV)8. Imaging was performed at DIV15, when synaptic transmission was absent, but before neuronal degeneration occurred. Lentiviral neuropeptide Y (NPY)-mCherry was used as a marker for neuropeptide release as reported before (van de Bospoort et al., 2012; Persoon et al., 2018) and SynaptophysinpHluorin as a marker for synaptic transmission (Granseth et al., 2006).

To rescue Munc18-1 KO neurons with the paralogs MUNC18-1, MUNC18-2, or MUNC18-3, we used previously described MUNC18-1, MUNC18-2, and MUNC18-3 plasmids (Toonen et al., 2006b; He et al., 2017; Santos et al., 2017) with Cre-EGFP coexpressed via a T2A cleavage-peptide sequence. Cre-EGFP fluorescence is confined to the nucleus and therefore does not preclude pHluorin-based DCV exocytosis analysis. Munc18-1 KO neurons were infected with these paralogs at DIV0 to ensure neuronal survival and viral concentrations were adjusted until similar survival rates were observed between conditions. For Munc18-1 KO rescue experiments and Munc18-1 HZ experiments, NPY-pHluorin and brain-derived neurotrophic factor (BDNF)-pHluorin were used as described before (De Wit et al., 2009; van de Bospoort et al., 2012; Farina et al., 2015; Persoon et al., 2018, 2019). 
A Single neuron island

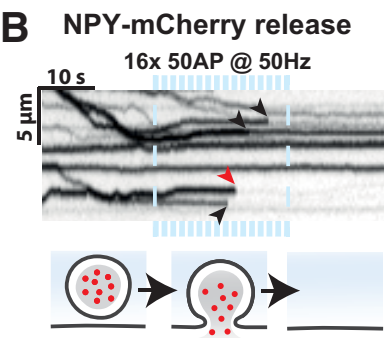

C NPY-mCherry release

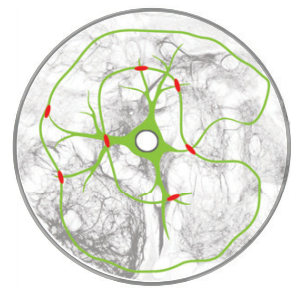

Cre-EGFP

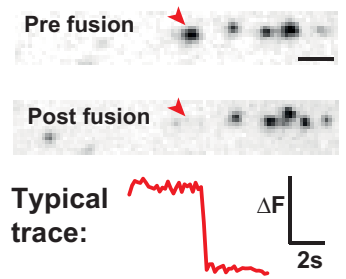

no $\mathrm{SV}$ release

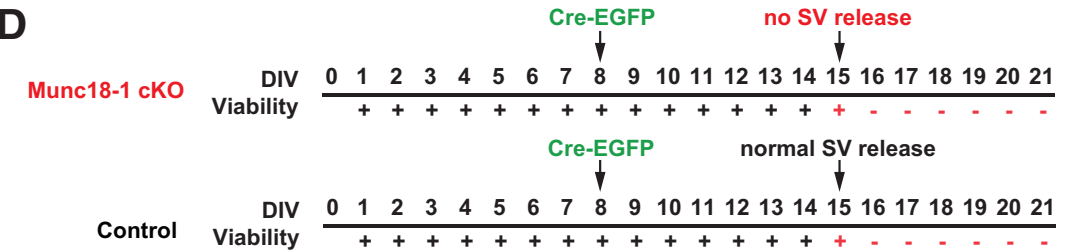

E

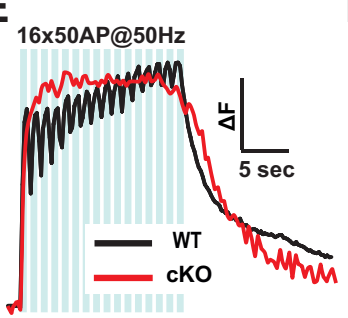

$\mathbf{F}$

H

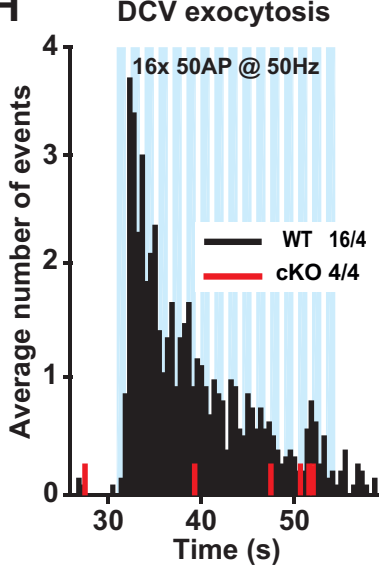

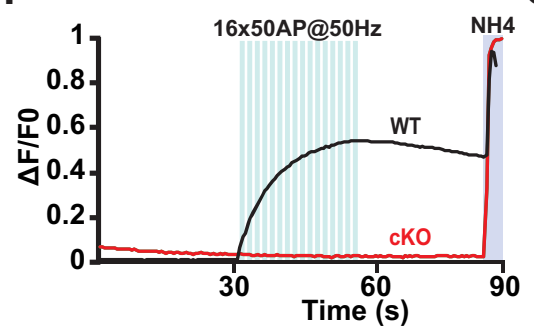

G

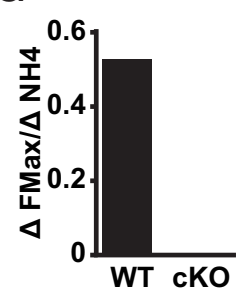

I Cumulative exocytosis

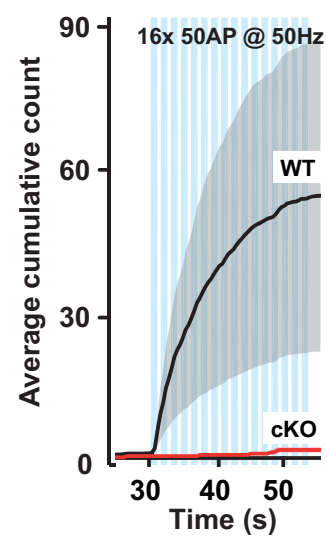

$J$ DCV exocytosis/cell

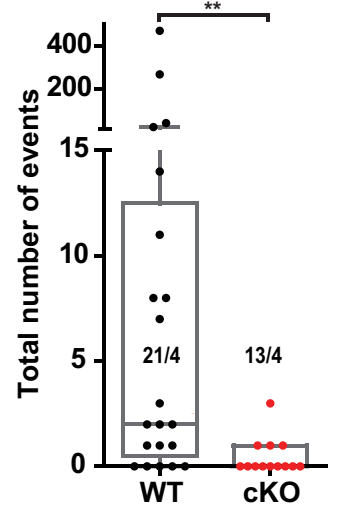

Figure 1. Munc18-1 is essential for DCV exocytosis in neurons. $A$, Schematic representation of a primary mouse hippocampal neuron grown on a glia microisland. $\boldsymbol{B}$, The kymograph shows NPY-mCherry fluorescence in an axonal stretch over time. During high-frequency train-stimulation indicated by blue bars (16 trains of $50 \mathrm{APs}$ at $50 \mathrm{~Hz}$ ), NPY-mCherry release events are visible as an abrupt termination of the line, marked by arrowheads. Below, Schematic model of an NPY-mCherry release event. C, Disappearance of a NPY-mCherry punctum visualized by two still frames: one before and one after the indicated exocytosis event (red arrowhead, same event as in $\boldsymbol{B}$ ). The typical trace shows the change in fluorescence $(\Delta F)$ over time measured from the indicated exocytosis event. $\boldsymbol{D}$, Isolated Munc18-1cK0 and WT (control) neurons infected at DIV8 with Cre-EGFP were tested for viability ( $+=$ viable, $-=$ non-viable) and for SV exocytosis using Synaptophysin-pHluorin (SypHy). $\boldsymbol{E}$, Typical $\mathrm{Ca}^{2+}$ traces during high-frequency burst-stimulation (16 trains of $50 \mathrm{APs}$ at $50 \mathrm{~Hz}$, blue bars), obtained using Flu05-AM, which increases fluorescence on Ca2 $^{+}$binding, in DIV14-DIV15 Munc18-1cKO (+ (re-EGFP) and WT (- Cre-EGFP) neurons. F, SV exocytosis assessed using SypHy in Munc18-1 cKO (+ Cre-EGFP) and WT (- Cre-EGFP) neurons. Fluorescence intensity increase reports $\mathrm{SV}$ exocytosis. $\mathrm{NH}_{4}{ }^{+}$is superfused at second 85 (indicated by gray shading) to dequench SypHy fluorescence in all SVs. G, Quantification of $\mathrm{F}: \Delta \mathrm{FMax} / \Delta \mathrm{NH}_{4}{ }^{+}$of SypHy in Munc18-1 cKO and WT neurons. $\boldsymbol{H}$, Histogram of the average number of DCV exocytosis events over time from non-silent Munc18-1 CKO neurons infected with $\Delta$ Cre (WT) or Cre (cKO). The blue bars indicate the stimulation paradigm. Sample size excluding silent neurons is visualized as $n / N$. $\boldsymbol{I}$, Cumulative representation of the data in $\boldsymbol{D}$. Error bars are SEM. $J$, The Tukey/scatter plot shows that the total number of DCV exocytosis events per cell is severely reduced in Munc18-1 CKO neurons (sample size is visualized as $n / M$ ). Mann-Whitney U test: ${ }^{* *} p<0.01$.

Western blotting

Munc18-1 null (KO) neurons were infected at DIV0 with Munc18-1, Munc18-2, or Munc183 containing lentiviral particles and harvested by scraping in ice-cold PBS at DIV14. Samples were centrifuged (12,000 rpm, $5 \mathrm{~min}$ ) and lysed in Laemmni sample buffer containing $2 \%$ SDS (VWR chemicals, M107), 10\% glycerol (Merck, 818709), 0.26 м $\beta$-mercaptoethanol (Sigma, M3148), 60mMTris-HCl (Serva, 37180) $\mathrm{pH}$ 6.8, and $0.01 \%$ bromophenol blue (Applichem, A3640). E18 brains from Munc18-1 KO and WT littermate and the spleen from an E18 WT embryo were triturated in ice-cold PBS before lysis in Laemmni sample buffer. Lysates were separated on $8 \%$ SDS-polyacrylamide gels. Proteins were transferred overnight at $150 \mathrm{~mA}$ and $4^{\circ} \mathrm{C}$ via wetblot transfer. Blocking was done with $2 \%$ BSA (Acros Organics, 268131000) in PBS with 0.1\% Tween 20 for $4 \mathrm{~h}$ at room temperature (RT). Blots were incubated with polyconal Munc18-1 (SySy 116003; Cijsouw et al., 2014; 1:1000), Munc18-2 (SySy 116102; 1:500), or Munc18-3 (Sigma HPA027255; 1:500) antibodies. Mouse monoclonal $\gamma$-Tubulin antibody (Sigma; T5326; $1: 1000$ ) was used as control for total protein levels. After washing with PBS $+0.1 \%$ Tween 20 , the blots were incubated with secondary antibodies (goat anti-mouse or anti-rabbit alkaline phosphatase-conjugated secondary antibodies 1:10,000; Jackson immunoresearch' in PBS with $2 \%$ BSA and $0.1 \%$ Tween 20 for $45 \mathrm{~min}$ at $4^{\circ} \mathrm{C}$. After washing, blots were incubated with AttoPhos substrate for $5 \mathrm{~min}$, scanned on a Fujifilm FLA-5000 Reader and analyzed with ImageJ software.

Live imaging

All live imaging experiments were performed between DIV14 and DIV18 at RT $\left(21-26^{\circ} \mathrm{C}\right)$. We used a custom-built set-up including an inverted microscope (IX81; Olympus) with an MT20 light source (Olympus), the appropriate filter sets (Semrock), a $40 \times$ oil objective (NA 1.3), an EM charge-coupled device camera (EMCCD; C9100-02; Hamamatsu Photonics) and Xcellence RT imaging software (Olympus). Electrical stimulation was delivered by parallel platinum electrodes placed around the gliaisland, conducting $30 \mathrm{~mA}, 1-\mathrm{ms}$ pulses controlled by a Master 8 system (AMPI) and a stimulus generator (A385RC, World Precision Instruments). A total of 16 or eight trains of 50 action potentials (APs) were generated at $50 \mathrm{~Hz}$ with 0.5 -s interval after $30 \mathrm{~s}$ of baseline recording. Imaging acquisition rate was $2 \mathrm{~Hz}$.

Coverslips were perfused with Tyrode's solution $\left(2 \mathrm{~mm} \mathrm{CaCl}_{2}, 2.5 \mathrm{mmKCl}, 119 \mathrm{~mm} \mathrm{NaCl}\right.$, $2 \mathrm{~mm} \mathrm{MgCl}, 30 \mathrm{~mm}$ glucose, and $25 \mathrm{~mm}$ HEPES; pH 7.4). pHluorin-based DCV exocytosis assays ended with a $10 \mathrm{~s} \mathrm{NH}_{4}{ }^{+}$perfusion (Tyrode's solution with $50 \mathrm{~mm} \mathrm{NH}_{4} \mathrm{Cl}$, replacing $50 \mathrm{~mm} \mathrm{NaCl}$ ), delivered via a gravity flow system with a capillary placed above the neuron, to de-quench pHluorin in all DCVs.

Analysis

In ImageJ (NIH), $2 \times 2$ pixel regions were placed on NPY-mCherry DCV exocytosis 
A NPY-pHluorin dequenching

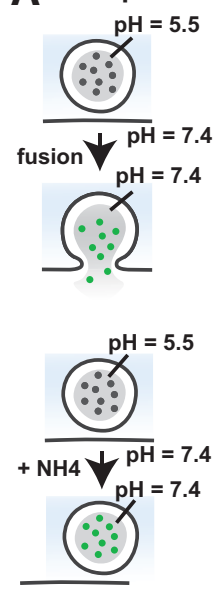

Pre stim.

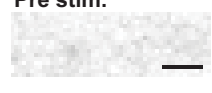

Stim.

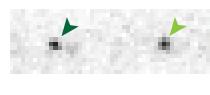

Typical traces

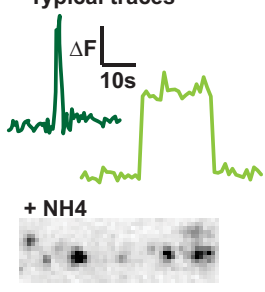

D

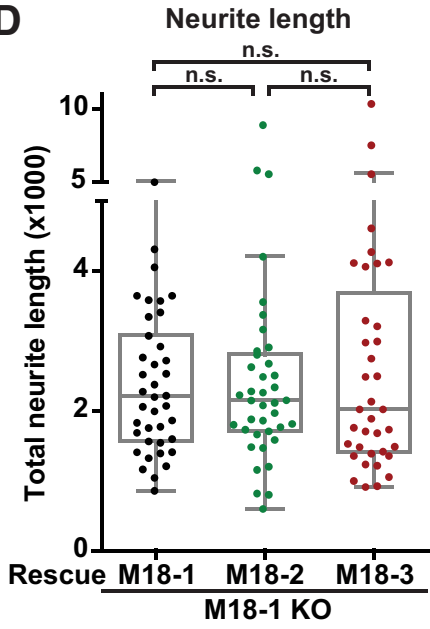

G

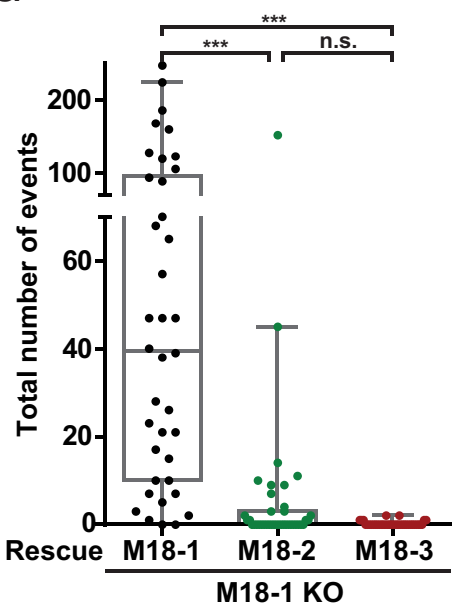

B NPY-pHluorin dynamics
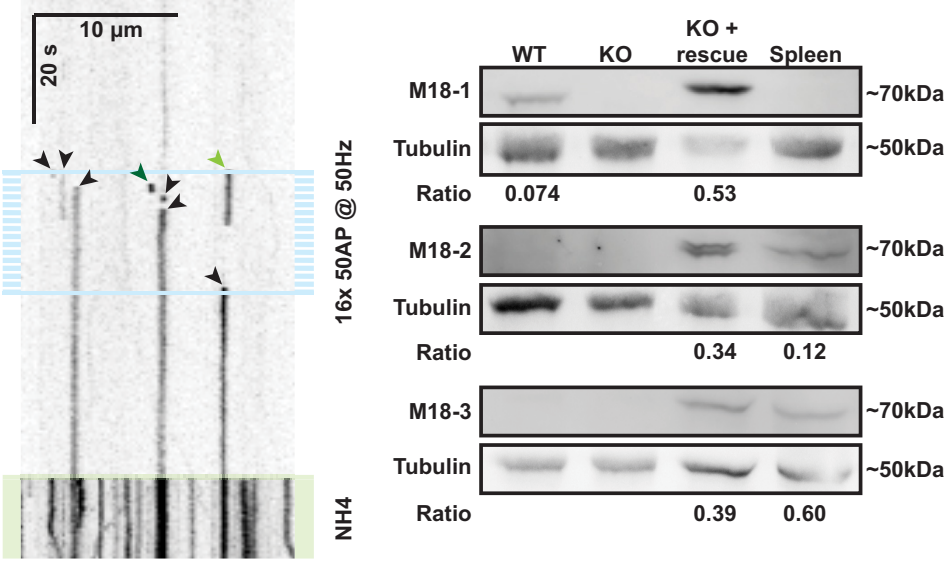

E

DCV exocytosis events

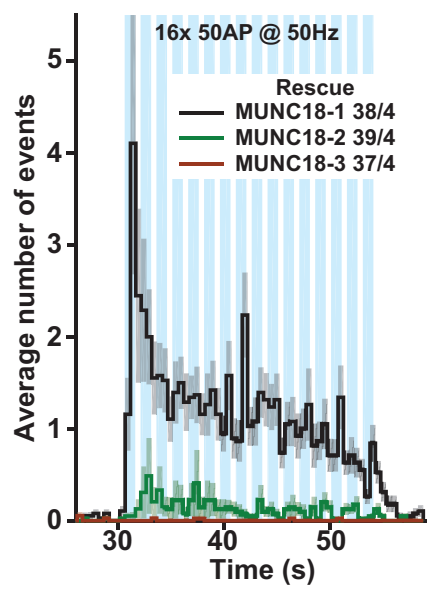

F Cumulative DCV exocytosis

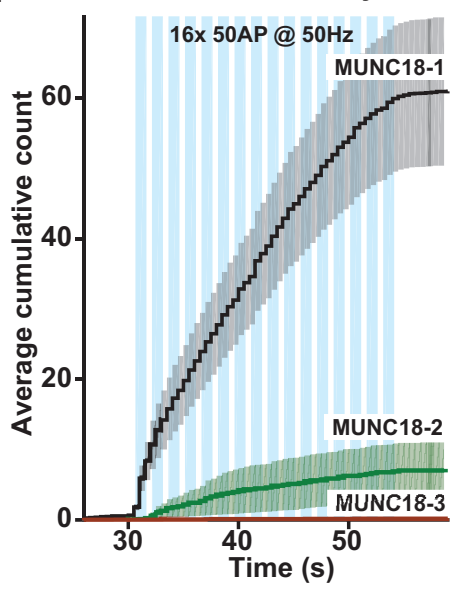

H
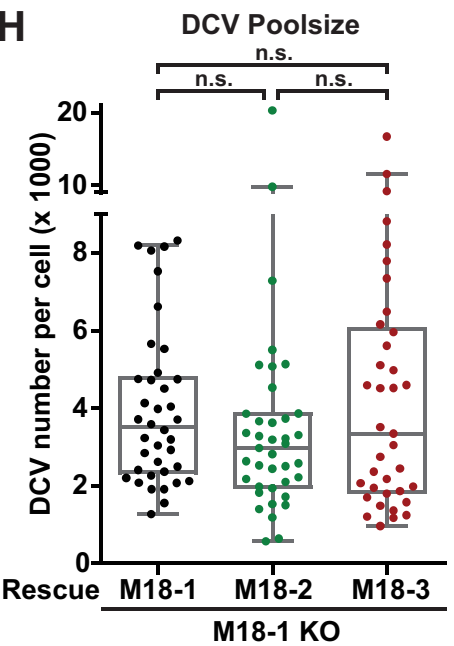

I

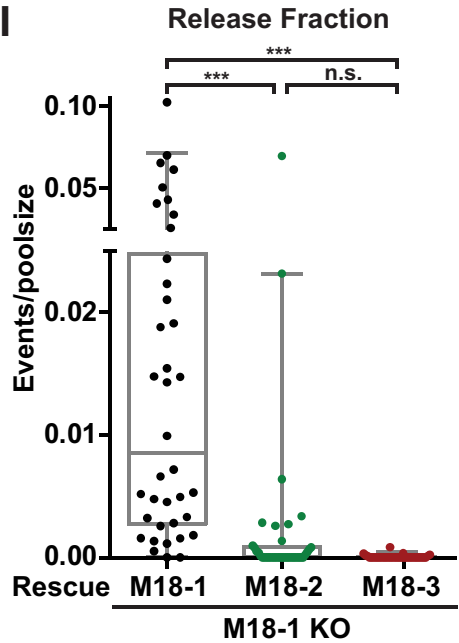

Figure 2. Expression of MUNC18-1, but not MUNC18-2 or MUNC18-3, supports DCV exocytosis in Munc18-1 null neurons. $\boldsymbol{A}$, left, Model showing the DCV cargo NPY-pHlluorin quenched at the low pH inside the vesicle, and de-quenched on vesicular pH elevation during an exocytosis event or $\mathrm{NH}_{4}{ }^{+}$application. Right, Still frames show an axonal stretch before and during stimulation, and during $\mathrm{NH}_{4}^{+}$perfusion. The line plots show changes in fluorescence $(\Delta \mathrm{F})$ over time measured from the exocytosis events indicated by the green arrows. Scale bar: $5 \mu \mathrm{m}$. $\boldsymbol{B}$, The kymograph shows an axonal stretch over time, visualizing NPY-pHluorin de-quenching events (arrowheads), caused by DCV exocytosis, as well as de-quenching caused by NH ${ }_{4}^{+}$(depicted by green-shading at the bottom). High-frequency train-stimulation is indicated with blue bars. The green arrowheads indicate the same exocytosis events as in $\boldsymbol{A}$. The black arrows indicate other visible exocytosis events. C, Lysates of primary WT neurons, Munc18-1 null (K0) neurons (DIV14-DIV18) or mouse spleen were separated via SDS-PAGE gel electrophoresis and immunoblotted for MUNC18-1 (M18-1), MUNC18-2 (M18-2), or MUNC18-3 (M18-3), and for $\gamma$-Tubulin (Tubulin) as loading control. Rescue of Munc18-1 K0 neurons (indicated with K0 + rescue, third lane) was done with Munc18-1 (top), Munc18-2 (middle), or Munc18-3 (bottom) containing lentivirus particles at DIV0. Ratio indicates intensity of MUNC18-1, MUNC18-2, or MUNC18-3 divided by tubulin, showing that MUNC18-1 rescue levels were higher than WT and that MUNC18-2 rescue levels were higher, while MUNC18-3 rescue levels were lower than endogenous levels in the spleen. D,The Tukey/scatter plot shows that the total neurite length of Munc18-1null neurons rescued with MUNC18-1, MUNC18-2, or MUNC18-3 is similar (same data set as in Fig. 2). Kruskal-Wallis with Dunn's correction: n.s. = non-significant. $\boldsymbol{E}$, Histogram showing the average number of NPY-pHluorin-labeled DCV exocytosis events in Munc18-1 null neurons rescued with 
events and $3 \times 3$ pixel regions were placed on NPY-pHluorin or BDNFpHluorin events. The ROI intensity measures were loaded into a custom written MATLAB (MathWorks) script for semi-automatic analysis, where each was plotted as change in fluorescence $(\Delta \mathrm{F})$ compared with baseline fluorescence (F0, average fluorescence during the first 10 frames). An exocytosis event was detected when $\Delta \mathrm{F}$ was at least $2 \mathrm{SDs}$ below or above F0 for respectively NPY-mCherry and NPY/BDNFpHluorin-labeled DCVs. Somatic events were excluded because of high background signal. Histograms and cumulative plots were generated in MATLAB. Further analysis including statistical tests and generation of Tukey/scatter plots was conducted in GraphPad Prism. The onset delay in DCV exocytosis was calculated for each neuron by subtracting the time point of the start of the simulation from the time point where $50 \%$ of the events have occurred.

To calculate the neurite length and total number of DCVs (poolsize) per neuron, the highest-intensity frame during $\mathrm{NH}_{4}$ perfusion was taken for pHluorin based assays and further analyzed using the MATLAB program SynD(Schmitz et al., 2011; van de Bospoort et al., 2012). Parameters were optimized for detection of DCVs and the number of detected DCVs was adjusted for intensity by dividing by the mode intensity.

Experimental design and statistical analysis

Statistical analysis was performed in GraphPad Prism (summarized in Table 1, which also includes experimental design). ShapiroWilk normality test was used to test for normal distributions and Levene's to test for homogeneity of variances. In all datasets at least one group was not normally distributed. Therefore, a MannWhitney $U$ test for data with two conditions and multiple comparisons were tested using a Kruskal-Wallis test followed by a Dunn's multiple comparisons post hoc test.

\section{Results}

\section{Munc18-1 is essential for DCV exocytosis in neurons}

To test which SM protein(s) drives DCV exocytosis in mammalian neurons, we used hippocampal neurons from conditional Munc18-1 null (cKO) mice grown on prepatterned glia microislands, each containing a single neuron infected with NPY-mCherry as a DCV exocytosis reporter (De Wit et al., 2009; Farina et al., 2015; Persoon et al., 2018; Fig. 1A). Neurons were infected with EGFP-tagged Cre-recombinase at DIV8 to induce Munc18-1 null, or with ineffective deltaCre (WT) as control. DCV exocytosis was triggered by high-frequency burst-stimulation $(16 \times 50$ APs at $50 \mathrm{~Hz}$; Fig. $1 B$ ) and individual release events, marked as sudden disappearance of mCherry fluorescence, were quantified over time (Fig. 1C).

As MUNC18-1 is essential for SV exocytosis (Verhage et al., 2000), we used the fluorescent SV exocytosis reporter Synaptophysin-pHluorin(Granseth et al., 2006) to assess the Credependent loss of MUNC18-1 protein in Munc18-1 cKO

MUNC18-1 (black), MUNC18-2 (green), or MUNC18-3 (brown). Sample size is indicated per condition as $n / N$. The blue bars indicate the stimulation paradigm. Error bars are SEM. $\boldsymbol{F}$, Cumulative representation of the data in $\mathbf{D}$. Error bars are SEM. $\mathbf{G}$, The Tukey/scatter plot shows that Munc18-1 null neurons rescued with MUNC18-2 or MUNC18-3 have a strong reduction in the total number of DCV exocytosis events per cell compared with MUNC18-1 rescued neurons. Kruskal-Wallis with Dunn's correction: ${ }^{* * *} p<0.001$. n.s. $=$ non-significant, $p>0.05$. $\boldsymbol{H}$, The Tukey/scatter plot shows that the total pool of DCVs per cell, revealed by $\mathrm{NH}_{4}$ application, is similar in Munc18-1 null neurons rescued with MUNC18-1, MUNC18-2, or MUNC18-3. Kruskal-Wallis with Dunn's correction: n.s. $=$ non-significant. $I$, The Tukey/scatter plot shows that in MUNC18-2 or MUNC18-3 rescued neurons, the number of DCV exocytosis events normalized by the poolsize (indicated as release fraction) is strongly reduced. Kruskal-Wallis with Dunn's correction: ${ }^{* * *} p<0.001$, n.s. $=$ non-significant. neurons. SV exocytosis was marked as an increase in fluorescence during burst stimulation in control neurons at DIV15 and was blocked in Munc18-1 cKO neurons that were infected $7 \mathrm{~d}$ earlier with Cre-EGFP, while calcium influx during stimulation was not significantly affected (Fig. $1 D-G$ ). In sister cultures at DIV15, control neurons showed NPY-mCherry release events throughout the $50 \mathrm{~Hz}$ burst stimulation, with the highest rate during the first few bursts, as shown before (Fig. 1H,I; Farina et al., 2015; Persoon et al., 2018, 2019). In contrast, virtually no NPY-mCherry release events occurred in Munc18-1 cKO neurons (Fig. $1 H-J$ ). Not a single release event was observed in $75 \%$ of these neurons (Fig. 1J). Hence, MUNC18-1 is essential for neuronal DCV exocytosis.

\section{Expression of MUNC18-1, but not MUNC18-2 or MUNC18- 3, supports DCV exocytosis in Munc18-1 null neurons}

For independent confirmation of the DCV exocytosis defect in Munc18-1 cKO neurons, we next used a different DCV exocytosis reporter in classical Munc18-1 null neurons. The $\mathrm{pH}$-sensitive DCV exocytosis reporter NPY-pHluorin, which has low basal fluorescence because of quenching at the low $\mathrm{pH}$ inside DCVs, and detects DCV fusion pore opening (van de Bospoort et al., 2012; Farina et al., 2015; Persoon et al., 2018). During high-frequency burst-stimulation, NPY-pHluorin marks DCV exocytosis events by a sudden increase in fluorescence on DCV fusion with the plasma membrane, followed by an immediate decrease (transient events representing fusion pore closure and vesicle reacidification or full cargo release) or delayed decrease (persistent events representing delayed reacidification or extracellular cargo deposition; Fig. $2 A, B$ ). To visualize the total DCV pool, neurons were superfused with $\mathrm{NH}_{4}{ }^{+}$at the end of each recording, de-quenching NPY-pHluorin in acidified compartments (Fig. 2A,B).

Munc18-1 null neurons degenerate in vitro and in vivo, which can be delayed by the trophic factors insulin and BDNF (Verhage et al., 2000; Heeroma et al., 2004). Viral expression of MUNC18-1, or its paralogs MUNC18-2 or MUNC18-3 completely rescues cell viability (He et al., 2017; Santos et al., 2017). To test which paralogs support DCV exocytosis, we expressed each paralog separately in Munc18-1 null neurons and quantified DCV exocytosis with NPY-pHluorin. All MUNC18 paralogs were detected on Western-blot, supported normal viability and neurons expressing any of these paralogs had a normal morphology, as reported before (Fig. 2C,D). Re-expression of MUNC18-1 in Munc18-1 null neurons resulted in robust DCV exocytosis on high-frequency burst-stimulation (Fig. $2 E-G$ ), comparable to WT neurons (see below). However, DCV exocytosis was severely impaired on expression of MUNC18-2 or MUNC18-3 (Fig. 2E$G)$. Not a single fusion event was observed in 56\% (MUNC18-2) and $81 \%$ (MUNC18-3) of the neurons (Fig. $2 G$ ). The total number of DCVs per neuron (DCV poolsize) was similar in all three conditions (Fig. $2 H$ ). DCV exocytosis normalized to the poolsize (release fraction) was normal in Munc18-1 null neurons reexpressing MUNC18-1, but severely impaired in Munc18-1 null neurons expressing MUNC18-2 or MUNC18-3 (Fig. 2I). These data show that MUNC18-1 re-expression supports stimulusevoked DCV exocytosis in Munc18-1 null neurons and that MUNC18-2 and MUNC18-3 do not support DCV exocytosis. In addition, MUNC18-1, MUNC18-2, and MUNC18-3 all support normal morphology and DCV biogenesis in Munc18-1 null neurons. 
Reduced expression in Munc18-1 HZ neurons leads to decreased DCV exocytosis

To characterize the role of MUNC18-1 in DCV exocytosis further, we quantified exocytosis events of NPY-pHluorin-labeled DCVs under conditions of reduced expression in Munc18-1 HZ neurons, which are shown to have $\sim 50 \%$ reduced MUNC18-1 expression levels (Toonen et al., 2006b; Kovacevic et al., 2018). First, Munc18-1 WT and Munc18-1 HZ neurons were stimulated with a high-frequency burst-stimulation $(16 \times 50 \mathrm{APs}$ at $50 \mathrm{~Hz}$ ). Munc18-1 HZ neurons showed a trend toward reduced DCV exocytosis, especially during the first two bursts $(2 \times 50$ APs; Fig. $3 A, B)$. Post hoc analysis of this initial phase indicated a $61 \%$ reduction in initial DCV exocytosis in Munc18-1 HZ neurons (Fig. 3C,D). The median DCV exocytosis onset delay, defined as the duration from the start of the stimulation until $50 \%$ of the DCV exocytosis events have occurred, was increased in Munc18-1 HZ (Fig. 3E). The total number of exocytosis events, the total DCV pool and release fraction were all not altered (Fig. $3 F-H$ ).

To seek independent confirmation of these effects, we stimulated Munc18-1 WT and HZ neurons in a new series of experiments with half the number of bursts (eight instead of 16), the same number of APs per burst (50) and the same frequency $(50 \mathrm{~Hz})$, followed by the same pattern $30 \mathrm{~s}$ later. DCV exocytosis in Munc18-1 HZ neurons was reduced throughout the first 8-burst train-stimulation, by $79 \%$ (Fig. 4A-C; Movies 1, 2). During this first 8-burst train-stimulation, the onset of exocytosis events was unaltered in Munc18-1 HZ neurons compared with WT neurons (Fig. $4 A, B, D$, $E)$. During the subsequent (second) eight-burst train-stimulation, both Munc18-1 WT and HZ neurons showed acceleration of DCV exocytosis compared with the first train-stimulation, indicated by a strong reduction in the median delay of DCV exocytosis relative to the start of the train-stimulation (Fig. 4A,B,D,E). DCV exocytosis was again reduced in $\mathrm{HZ}$ neurons during the second stimulation, with a smaller effect size than during the first stimulation (60\% reduction; Fig. $4 A, B$, $F$; Movies 1,2), resulting in a median reduction of $69 \%$ over the two eighttrains. As a measure for potentiation of DCV exocytosis, the number of exocytosis events during the second stimulation was divided by the number of events
A

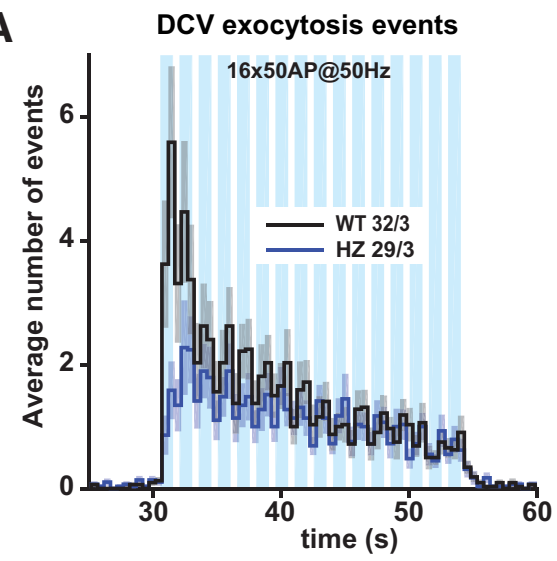

C Norm. cum. exocytosis

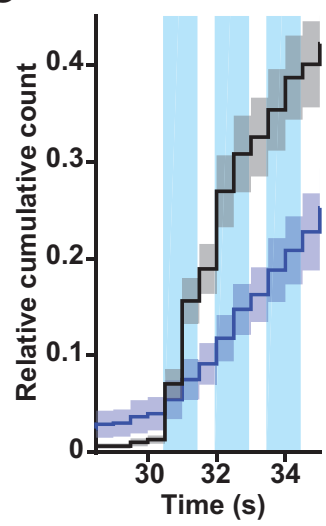

F DCV exocytosis/cell

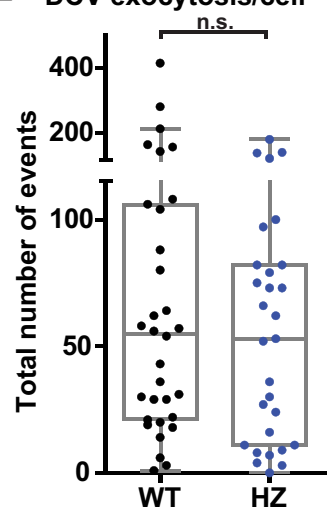

B

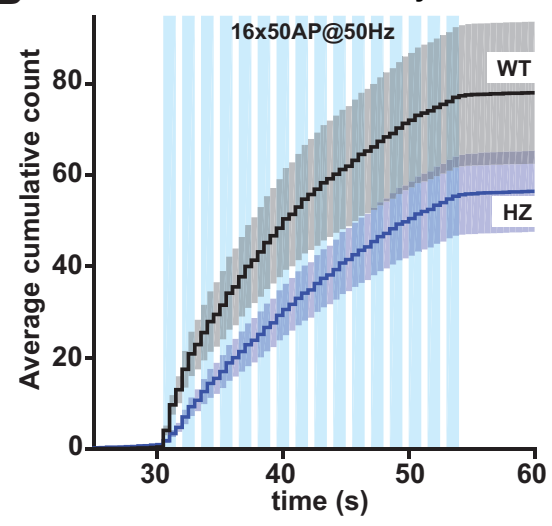

D Early DCV exocytosis

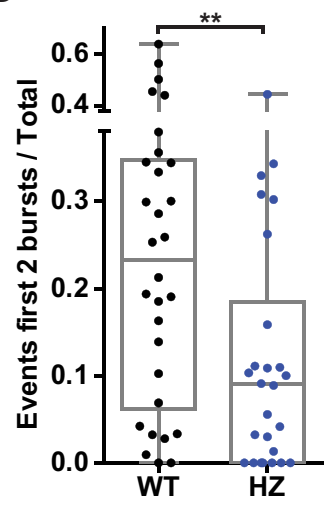

G

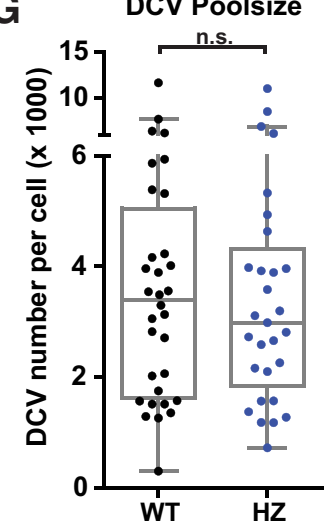

E DCV exocytosis delay

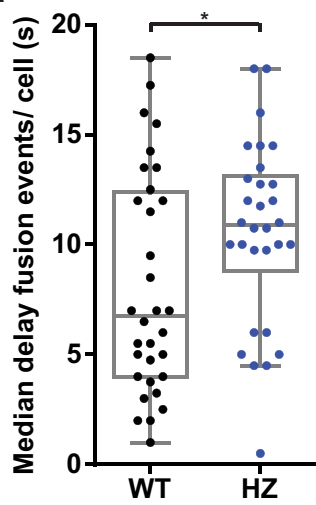

$\mathrm{H}$

H Release fraction

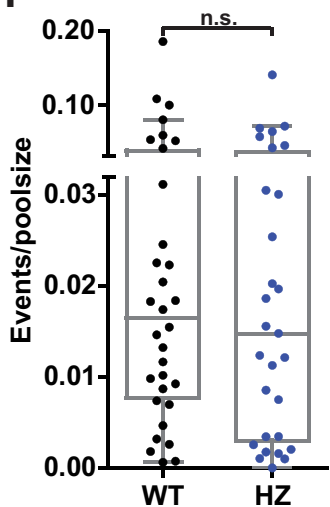

Figure 3. Reduced MUNC18-1 levels decrease DCV exocytosis during the first seconds of stimulation. $\boldsymbol{A}$, The histogram shows the average number of DCV exocytosis events for Munc18-1 WT (black) and Munc18-1 HZ (blue) neurons over time (sample size is indicated as $n / N$ ). Error bars are SEM. $\boldsymbol{B}$, Cumulative representation of the data in $\boldsymbol{A}$. Error bars are SEM. WT exocytosis levels varied between experiments, probably because of changes in medium batches. $\boldsymbol{C}$, Normalized cumulative representation of the data in $\boldsymbol{A}$ during the first seconds of train-stimulation. Error bars are SEM. D. The Tukey/scatter plot shows that the relative DCV exocytosis during the first two trains of stimulation is decreased in Munc18-1 HZ neurons. This was calculated per cell by dividing the number of events during the first two seconds of stimulation by the total number of exocytosis events of that cell. Mann-Whitney test: ${ }^{* *} p<0.01$. $\boldsymbol{E}$, The Tukey/scatter plot shows that the median delay of DCV exocytosis events relative to the start of the train-stimulation is larger in Munc18-1 HZ neurons comparted to WT. MannWhitney test: ${ }^{*} p<0.05$. $\boldsymbol{F}$, The Tukey/scatter plot shows the number of DCV exocytosis events for Munc18-1 WT and $\mathrm{HZ}$ neurons. Mann-Whitney test: n.s. = non-significant. G, The Tukey/scatter plot shows the total number of DCVs, extracted from $\mathrm{NH}_{4}{ }^{+}$superfusion at the end of each recording, for Munc18-1 WT and HZ neurons. Mann-Whitney test: $n$.s. $=$ non-significant. $\boldsymbol{H}$, The Tukey/scatter plot shows the number of DCV exocytosis events normalized by the poolsize (release fraction) for Munc18-1 WT and HZ neurons. Mann-Whitney test: n.s. $=$ non-significant. 
A
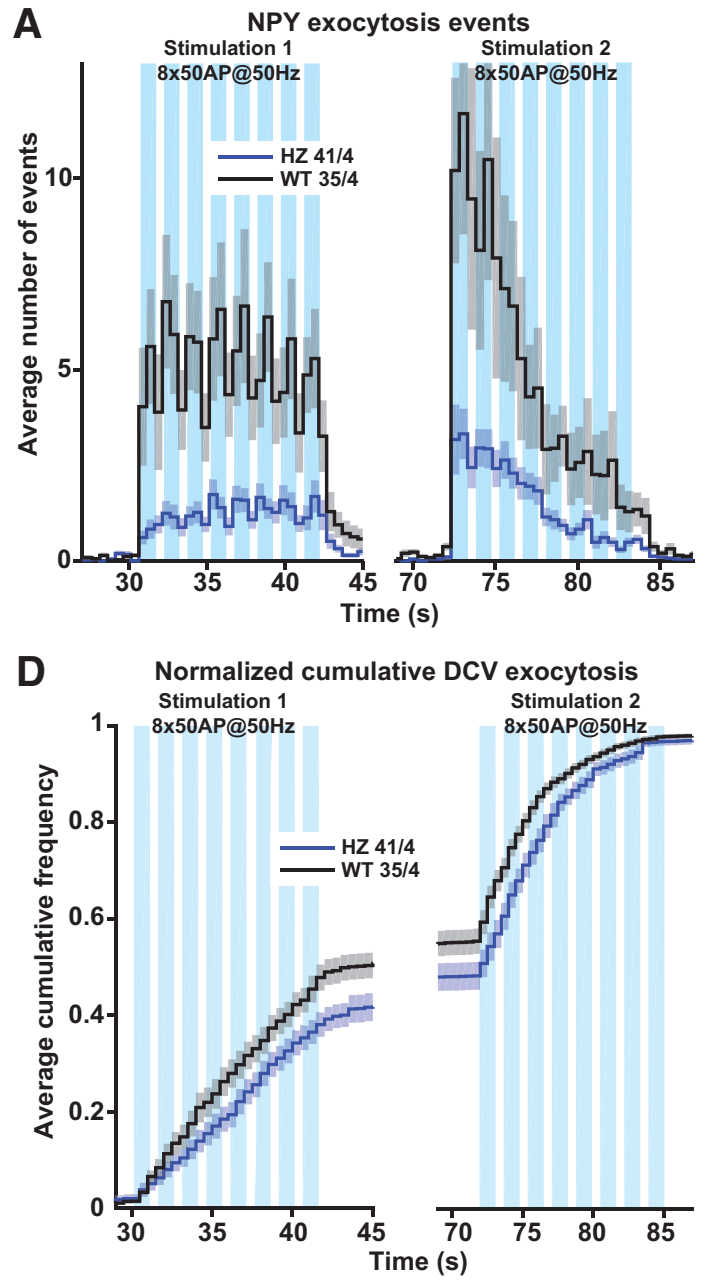

B

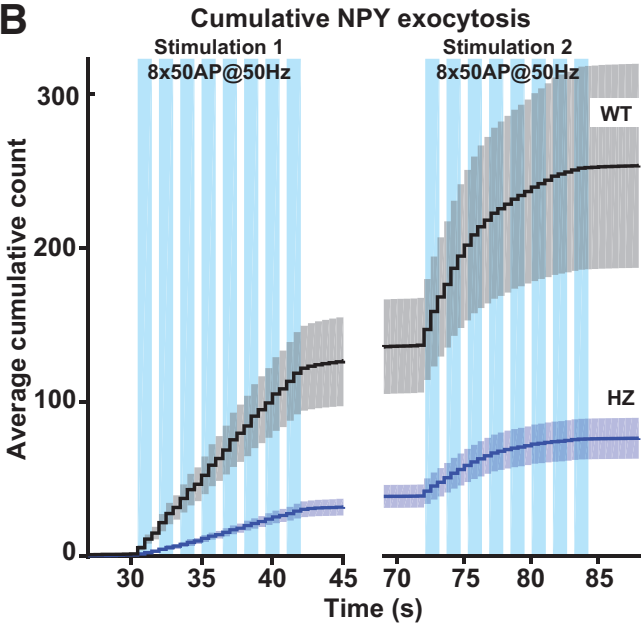

E NPY-pHluorin exocytosis onset

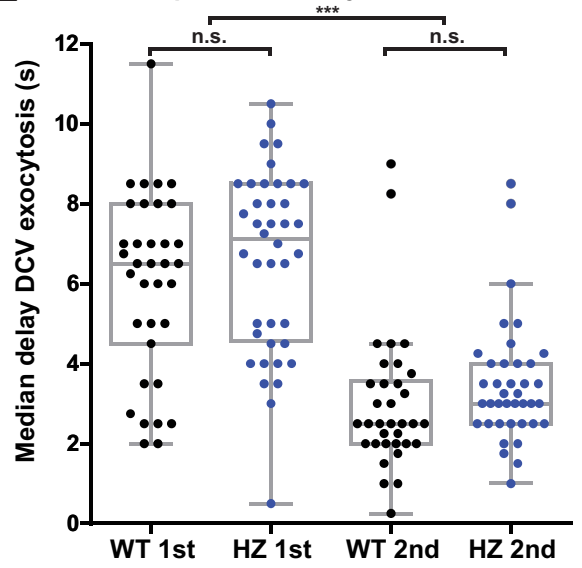

C NPY exocytosis Stim. 1

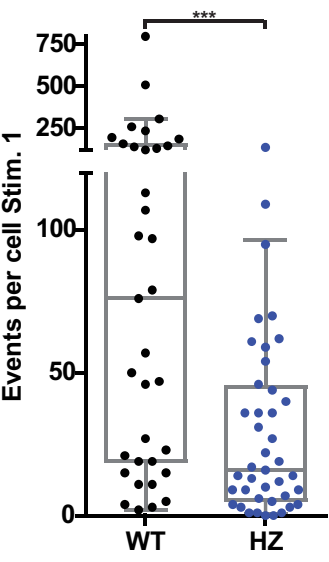

F NPY exocytosis Stim. 2

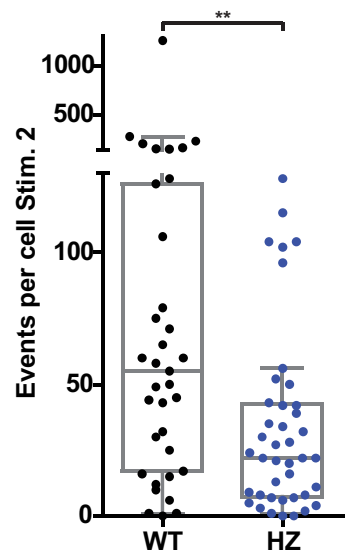

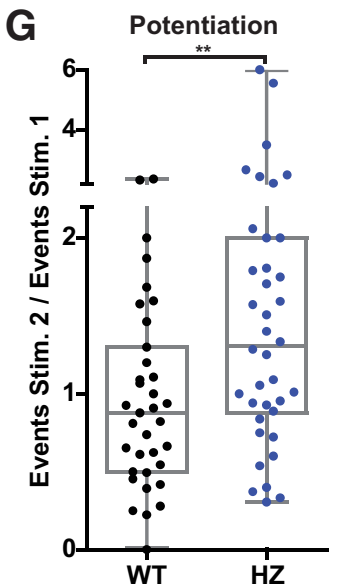
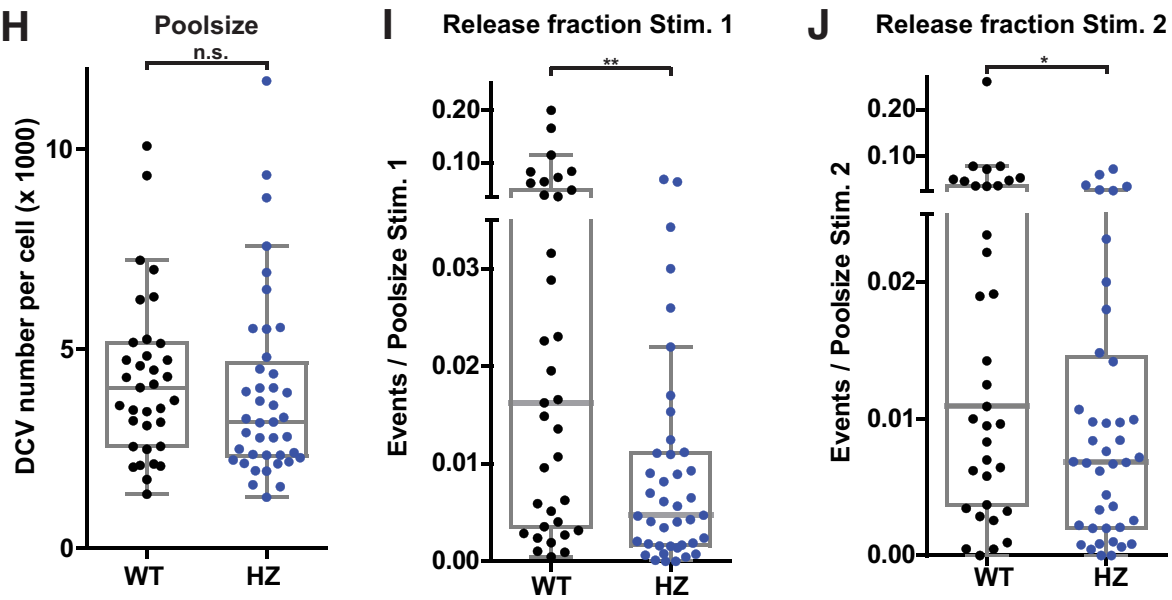

Figure 4. Munc18-1 HZ inactivation reduces exocytosis of NPY-pHluorin-labeled DCVs. A, The histogram shows the average number of DCV exocytosis events for Munc18-1 WT (black) and $\mathrm{HZ}$ (blue) neurons that were infected with NPY-pHluorin (sample size is indicated as $n / N)$. The blue bars indicate the two stimulation paradigms $(8$ times $50 \mathrm{APs}$ at $50 \mathrm{~Hz})$. Error bars are SEM. $\boldsymbol{B}$, Cumulative representation of the data in $\boldsymbol{A}$. Error bars are SEM. $\boldsymbol{C}$, The Tukey/scatter plot shows that the number of DCV exocytosis events per cell during the first train-stimulation is decreased in Munc18-1 HZ neurons. Mann-Whitney $U$ test: ${ }^{* * *} p<0.001$. In this experiment, Munc18-1 WT neurons had higher absolute numbers of DCV exocytosis compared with those in Figure 3. $\boldsymbol{D}$, Normalized cumulative representation of the data in $\boldsymbol{A}$. Error bars are SEM. $\boldsymbol{E}$, The Tukey/scatter plot shows the median delay of DCV exocytosis events, relative to the start of each train-stimulation, for Munc18-1 WT and HZ neurons. The delay within each train-stimulation is similar between Munc18-1 WT and HZ neurons. During the second train-stimulation, in both WT and $\mathrm{HZ}$ neurons, the median delay of exocytosis is decreased compared with the first stimulation. Kruskal-Wallis with Dunn's correction: ${ }^{* * *} p<0.001$, n.s. $=$ non-significant. $\boldsymbol{F}$, The Tukey/ scatter plot shows that the number of DCV exocytosis events per cell during the second train-stimulation is decreased in Munc18-1 HZ neurons. Mann-Whitney $U$ test: ${ }^{* *} p<0.01$. G, The Tukey/scatter plot shows that the ratio of the number of exocytosis events between the second and first train-stimulation (potentiation) is higher in Munc18- $1 \mathrm{HZ}$ neurons. Mann-Whitney $U$ test: **p $<0.01$. $\boldsymbol{H}$, The Tukey/scatter plot shows that Munc18- 1 WT and HZ neurons have a similar total pool of DCVs, as revealed by NH ${ }_{4}$ application. Mann-Whitney $U$ test: $n$.S. $=$ non-significant. $I$, The Tukey/scatter plot shows that the number of DCV exocytosis events normalized by the total pool (indicated as release fraction) was decreased in Munc18-1 HZ neurons during the first train-stimulation. Mann-Whitney $U$ test: ${ }^{* *} p<0.01$. J, The Tukey/scatter plot shows that the number of DCV exocytosis events normalized by the total pool (indicated as release fraction) was decreased in Munc18-1 HZ neurons during the second train-stimulation. Mann-Whitney $U$ test: ${ }^{*} p<0.01$. 


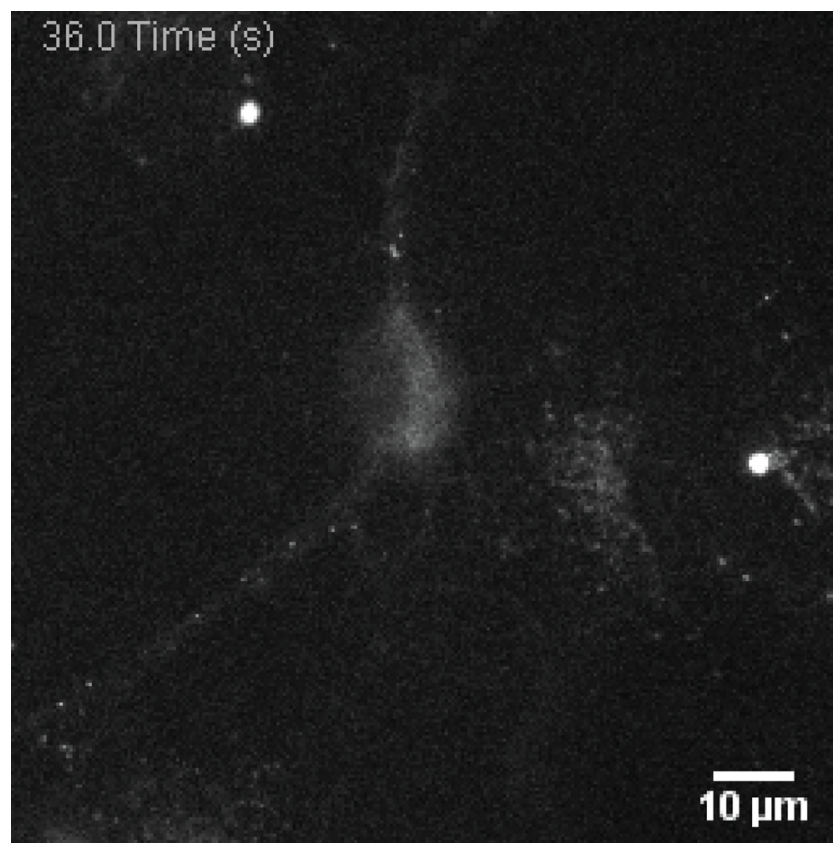

Movie 1. NPY-pHluorin-labeled DCV exocytosis events in WT neuron. Neuron was stimulated with two episodes consisting of eight bursts of $50 \mathrm{APs}$ at $50 \mathrm{~Hz}$. The first episode of train-stimulation starts at $30 \mathrm{~s}$, the second stimulation starts $30 \mathrm{~s}$ after the end of the first stimulation (which is at $72 \mathrm{~s}$ ). NPY-pHluorin-labeled DCV exocytosis events are visible as appearing puncta, mostly during the train-stimulations. From $113 \mathrm{~s}, \mathrm{NH}_{4}{ }^{+}$perfusion starts, which dequenches all NPY-pHluorin in acidic compartments, labeling the total DCV pool. [View online]

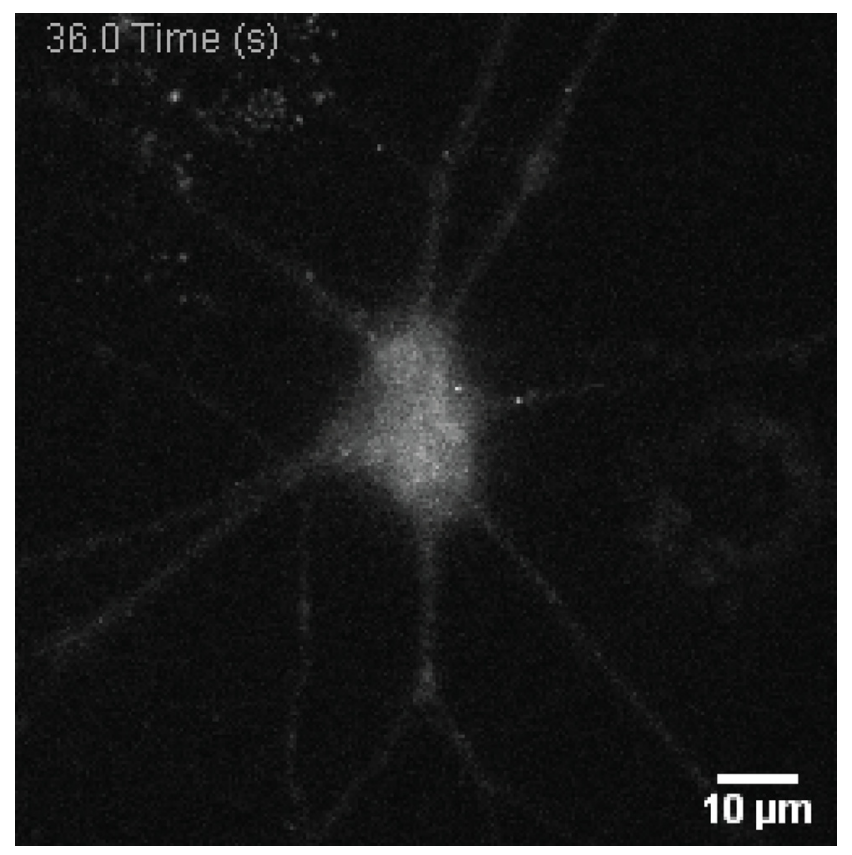

Movie 2. NPY-pHluorin-labeled DCV exocytosis events in Munc18-1 HZ neuron. Neuron was stimulated with two episodes consisting of eight bursts of $50 \mathrm{APs}$ at $50 \mathrm{~Hz}$. The first episode of train-stimulation starts at $30 \mathrm{~s}$, the second stimulation starts $30 \mathrm{~s}$ after the end of the first stimulation (which is at $72 \mathrm{~s}$ ). NPY-pHluorin-labeled DCV exocytosis events are visible as appearing puncta, mostly during the train-stimulations. From $113 \mathrm{~s}, \mathrm{NH}_{4}{ }^{+}$perfusion starts, which dequenches all NPY-pHluorin in acidic compartments, labeling the total DCV pool. [View online] during the first stimulation. DCV exocytosis in Munc18-1 HZ neurons showed a potentiation effect during the second trainstimulation, whereas this was absent in WT neurons (Fig. 4G). The total DCV pool was similar between genotypes (Fig. $4 H$ ). Consequently, DCV exocytosis normalized by the poolsize was significantly reduced during both stimulations in Munc18-1 HZ neurons (Fig. 4I,J).

To assess the overall effect of reduced MUNC18-1 expression on DCV exocytosis in both datasets (Figs. 3, 4), we performed a meta-analysis combining the data of the first eight bursts of 50 APs from both experiments. This analysis revealed that DCV exocytosis was reduced by $56 \%$ during the first eight bursts of high-frequency stimulation (Fig. $5 A-C$ ). The total number of DCVs and the total neurite length were not altered, and as a consequence, DCV exocytosis normalized to the total DCV pool was reduced by $56 \%$ (Fig. $5 D-F$ ). Taken together, these data show that HZ inactivation of Munc18-1 decreased DCV exocytosis, with a relatively stronger effect during the first stimulation, while acceleration of DCV exocytosis during the second stimulation stayed intact.

Finally, to test whether the reduction of DCV exocytosis in Munc18-1 HZ neurons generalizes to different DCV cargo types, we used the neurotrophin release reporter BDNF-pHluorin as an alternative DCV cargo. The total number of BDNF-pHluorin exocytosis events in both genotypes was at least twice as high as with NPY-pHluorin (Figs. 4A,B,C,F, 6A-D). Munc18-1 HZ neurons expressing BDNF-pHluorin and stimulated with two episodes of eight-burst train-stimulation of $50 \mathrm{APs}$ at $50 \mathrm{~Hz}$ showed a $36 \%$ reduced DCV exocytosis during the first stimulation, with a similar, albeit smaller, effect during the second stimulation (Fig. $6 A-D$ ), resulting in a median reduction of $43 \%$ over the two eight-trains compared with WT. Exocytosis in Munc18-1 HZ neurons was potentiated during the second train-stimulation, whereas this effect was absent in WT neurons (Fig. 6E). The acceleration of release during the second eight-train was similar to the previous experiment using NPY-pHluorin and similar for both genotypes (Fig. 6F,G). The total DCV pool was again similar between experimental groups and consequently DCV exocytosis normalized to the total pool was reduced during the first stimulation, but less pronounced during the second stimulation (Fig. $6 H-J)$. Hence, HZ inactivation of Munc18-1 and a 50\% reduced protein level decreased DCV exocytosis substantially, independent of DCV cargo, with a relatively stronger effect during the first stimulation.

\section{Discussion}

Here, we report that MUNC18-1 is essential for DCV exocytosis in hippocampal neurons. Live imaging of fluorescent reporters showed that Munc18-1 inactivation abolished neuropeptide release. Expression of paralogs MUNC18-2 or MUNC18-3 did restore cell viability but not DCV exocytosis. Furthermore, Munc18-1 HZ inactivation impaired DCV exocytosis. Hence, neurons critically and selectively depend on MUNC18-1 for DCV exocytosis.

We previously showed that neurotransmitter secretion critically depends on MUNC18-1 (Verhage et al., 2000). Our current data demonstrates that this is also true for neuropeptide secretion (Figs. 1, 2). SVs and DCVs share many other components of their exocytosis machinery (van de Bospoort et al., 2012; Cao et al., 2013; Südhof, 2013; Farina et al., 2015; Shimojo et al., 2015; Arora et al., 2017; Persoon et al., 2019; Hoogstraaten et al., 2020); however, several properties are strikingly different. DCVs require 
A DCV exocytosis events

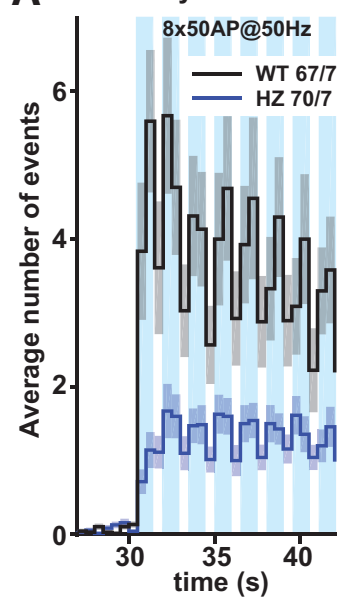

D DCV poolsize

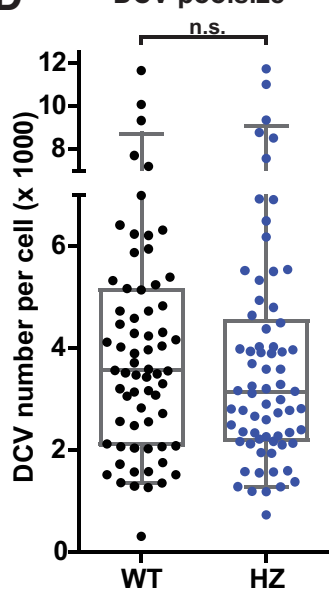

B Cumulative exocytosis

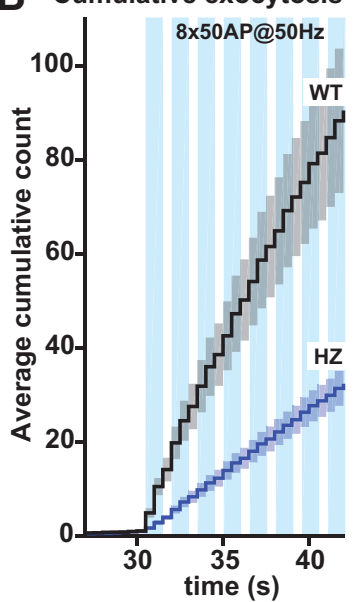

E Neuronal outgrowth

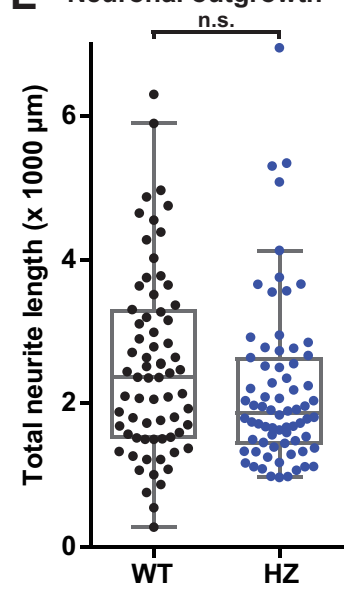

C DCV exocytosis/cell

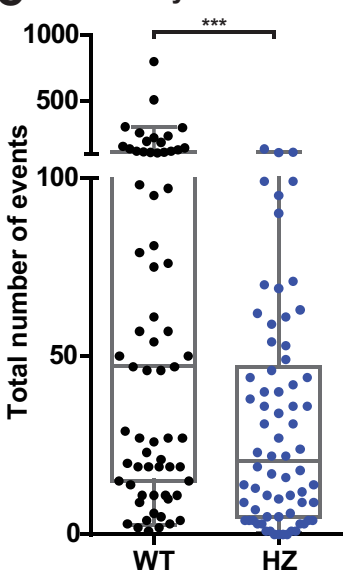

F Release fraction

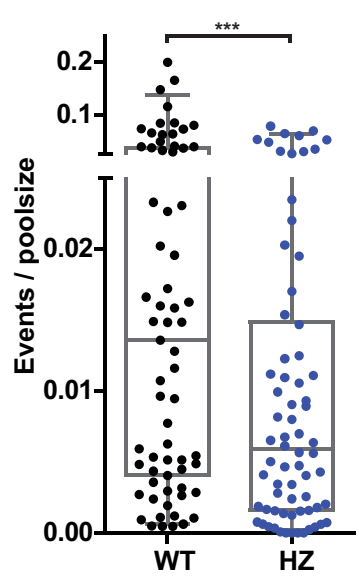

Figure 5. Meta-analysis: Munc18-1 $\mathrm{HZ}$ inactivation reduces DCV exocytosis. $\boldsymbol{A}$, The histogram shows the average number of DCV exocytosis events of Munc18-1 WT (black) and HZ (blue) neurons infected with NPY-pHluorin (sample size is indicated as $n / M$ ), during the first eight bursts of high-frequency train-stimulation (combined meta-analysis of datasets from Figs. 3, 4). Error bars are SEM. $\boldsymbol{B}$, Cumulative representation of the data in $\boldsymbol{A}$. Error bars are SEM. $\boldsymbol{C}$, The Tukey/scatter plot shows that the number of DCV exocytosis events is decreased in Munc18-1 HZ neurons during the first eight bursts of high-frequency trainstimulation. Mann-Whitney $U$ test: ${ }^{* *} p<0.001$. D, The Tukey/scatter plot shows the total number of DCVs for Munc18-1 WT and $\mathrm{HZ}$ neurons, revealed by $\mathrm{NH}_{4}{ }^{+}$superfusion. Mann-Whitney $U$ test: n.s. $=$ non-significant. $E$, The Tukey/scatter plot shows the total neurite length of Munc18-1 WT and HZ neurons. Mann-Whitney $U$ test: n.s. $=$ non-significant. $\boldsymbol{F}$, The Tukey/scatter plot shows that the number of DCV exocytosis events normalized by the poolsize (indicated as release fraction) is reduced in Munc18-1 HZ neurons during the first eight bursts of high-frequency train-stimulation. Mann-Whitney $U$ test: $p<0.001$.

a much higher number of APs to trigger exocytosis and fuse with a much longer delay after the start of stimulation (Zucker, 1973; Rosenmund et al., 1993; Murthy et al., 1997; Persoon et al., 2018). Additionally, while SV exocytosis is generally confined to specialized presynaptic release sites (active zones), DCVs exocytosis frequently occurs at non-synaptic locations (Südhof and Rizo, 2011; van de Bospoort et al., 2012; Persoon et al., 2018) and synaptic DCV exocytosis may be outside the active zone. It is puzzling that the only mechanistic difference for the final stages of either pathways is the critical requirement of RAB3A in DCV but not SV exocytosis (Schlüter et al., 2004, 2006; Persoon et al., 2018). This seems insufficient to explain the strikingly different properties of the two pathways.

Endogenous expression of Munc18-2 and Munc18-3 is insufficient to support neuronal viability, synaptic transmission or DCV exocytosis in Munc18-1 null neurons (Fig. 1; Santos et al., 2017; Verhage et al., 2000). Overexpression of MUNC18-2 or MUNC18-3 in Munc18-1 null neurons compensates for the absence of MUNC18-1 and restores viability, but does not support synaptic transmission or DCV exocytosis (Fig. 2; He et al., 2017; Santos et al., 2017). Hence, MUNC18-1 is the only MUNC18 paralog capable of supporting neuropeptide and neurotransmitter release in mouse CNS neurons. Likewise, only one SM-protein (MUNC18-2) mediates secretion from several blood cell types (Côte et al., 2009; Hackmann et al., 2013; Gutierrez et al., 2018; Cardenas et al., 2019), and different MUNC18 paralogs support distinct phases of secretion in the pancreas and lung (Oh and Thurmond, 2009; Oh et al., 2012; Lam et al., 2013; Jaramillo et al., 2019). Conversely, overexpression of MUNC18-2 in Munc18-1 null chromaffin cells partly rescues DCV exocytosis (Gulyás-Kovács et al., 2007). Hence, with few exceptions, SM-proteins have highly specialized roles in different forms of regulated secretion, with little or no redundancy among its paralogs. In contrast, the (unknown) function of MUNC18-1 in neuronal viability (Santos et al., 2017) as well as its role in regulating the actin cytoskeleton (Pons-Vizcarra et al., 2019), show ample redundancy among SM-proteins.

We previously showed synaptic assembly of the brain and cortical layering in the absence of synaptic transmission in Munc18-1null mice (Verhage et al., 2000). Our current data suggest that in Munc18-1 null brains, secretion of neuropeptides, neurotrophic factors, and axon guidance molecules from DCVs may be defective as well, implying that synaptic assembly and cortical layering do not require both secretory pathways. However, we cannot exclude that other, MUNC18-1 independent, secretion pathways may play a role during early brain development. Furthermore, one study recently challenged the conclusion that MUNC18-1 is dispensable for cortical layering of the brain, using more transient interference with MUNC18-1 expression in a small fraction of developing neurons (Hamada et al., 2017). Such a role in brain development may be supported by DCV exocytosis, e.g., by BDNF release (Schwartz et al., 1997; Borghesani et al., 2002; Medina et al., 2004; Zhou et al., 2007).

Neuropeptide/neurotrophin signaling is also associated with at least two other aspects of brain development. First, NPY and BDNF promote neural stem cell proliferation and differentiation during development (Hansel et al., 2001; Zhang et al., 2011; Chen et al., 2013). Second, BDNF signaling promotes layer-specific branching of callosal axons in vivo(Shimojo et al., 2015) and self-amplifying BDNF signaling underlies axonal differentiation and growth in vitro(Cheng et al., 2011). Therefore, it seems plausible that neuropeptides/neurotrophins are released during early brain development in Munc18-1 null mice, potentially via constitutive secretion. 

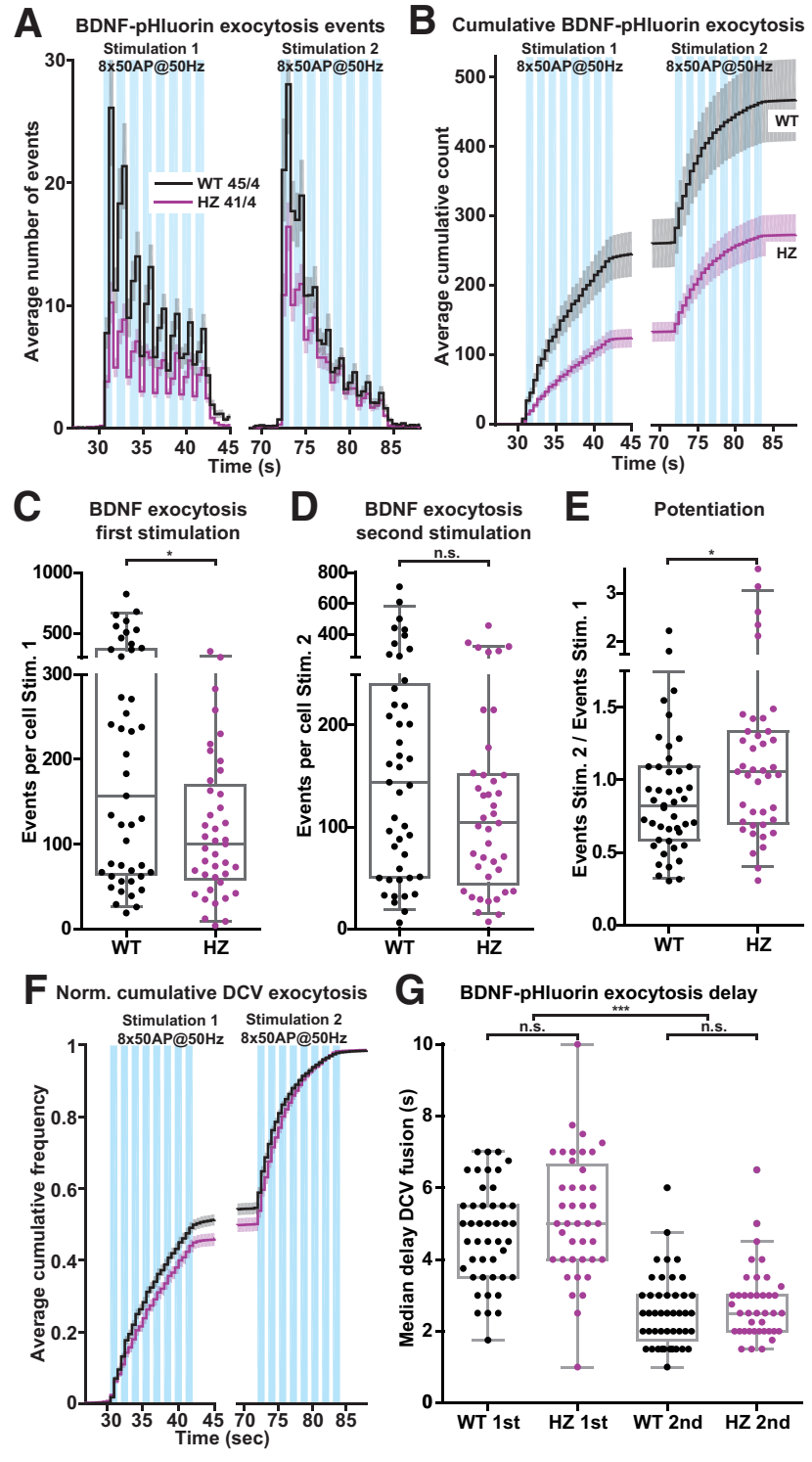

G BDNF-pHluorin exocytosis delay
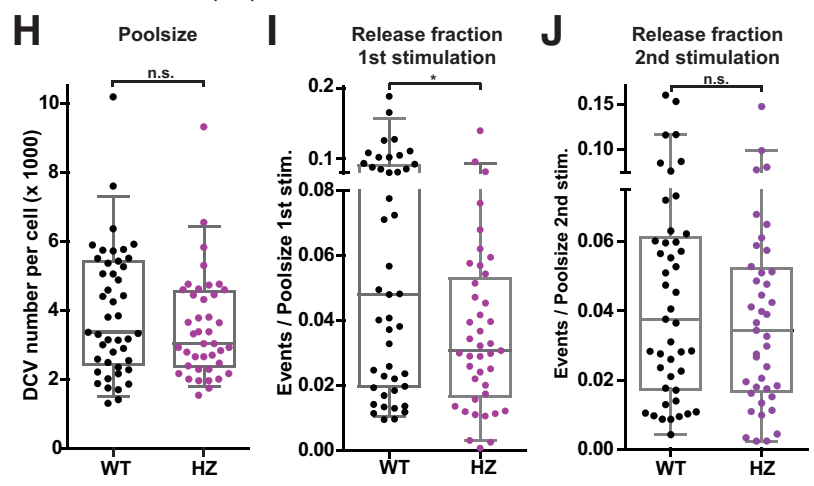

Figure 6. $\mathrm{HZ}$ inactivation of Munc18-1 reduces exocytosis of BDNF-pHluorin-labeled DCVs. $\boldsymbol{A}$, The histogram shows the average number of DCV exocytosis events for Munc18-1 WT (black) and $\mathrm{HZ}$ (magenta) neurons infected with BDNF-pHluorin (sample size is indicated as $n / M$ ). The blue bars indicate the two stimulation paradigms ( 8 times $50 \mathrm{APs}$ at $50 \mathrm{~Hz}$ ). Error bars are SEM. $\boldsymbol{B}$, Cumulative representation of the data in $\boldsymbol{A}$. Error bars are SEM. $\boldsymbol{C}$, The Tukey/scatter plot shows that the total number of DCV exocytosis events during the first train-stimulation is decreased in Munc18- $1 \mathrm{HZ}$ neurons. Mann-Whitney $U$ test: ${ }^{*} p<0.05$. $D$, The Tukey/scatter plot shows the total number of DCV exocytosis events during the second train-stimulation for Munc18-1 WT and HZ neurons. Mann-Whitney $U$ test: n.s. = non-significant. $\boldsymbol{E}$, The Tukey/scatter plot shows that the ratio of the number of exocytosis events between the second and first train-stimulation (potentiation) is higher in Munc18-1 HZ
BDNF-pHluorin and NPY-pHluorin label a largely overlapping population of DCVs (De Wit et al., 2009; Persoon et al., 2018), but NPY-pHluorin exocytosis events in WT neurons occurred $50 \%$ less frequently than BDNF-pHluorin events on the same stimulation (Figs. 4, 6). Numbers of NPY-pHluorin-labeled or BDNF-pHluorin-labeled DCVs were similar (Figs. 4, 6). NPY is inhibits synaptic transmission (Raposinho et al., 1999; Tschenett et al., 2003), while BDNF stimulates spontaneous and evoked synaptic transmission (Collin et al., 2001; Tartaglia et al., 2001; Tyler and Pozzo-Miller, 2001; Shinoda et al., 2014). Our data suggest that NPY and BDNF exert a similar effect on DCV exocytosis.

We observed a different effect size between two datasets obtained with NPY-pHluorin (Figs. 3, 4), possibly because of differences in culture conditions (supplements, coatings). However, meta-analysis on both data-sets shows clearly reduced DCV exocytosis on HZ Munc18-1 inactivation (Fig. 5). To confirm this conclusion with an independent line of evidence, we used DCV exocytosis marker BDNF-pHluorin, and also observed reduced DCV exocytosis in Munc18-1 HZ neurons (Fig. 6). Hence,HZ Munc18-1 inactivation reduces DCV exocytosis almost proportionally, by $36-56 \%$ (Figs. 6, 4, respectively), while protein levels are 50\% reduced (Verhage et al., 2000; Toonen et al., 2005, 2006b; Lee et al., 2019). In contrast, HZ Munc18-1 inactivation barely affected chromaffin cell secretion, although docking was $\sim$ 3-fold reduced (Toonen et al., 2006a), and hippocampal synapses from Munc18-1 HZ mice had a normal first evoked response (Toonen et al., 2006b). This suggests that DCV exocytosis is generally more vulnerable to reduced MUNC18-1 protein levels than other regulated secretion pathways. However, specific synapses in the brains of Munc18-1 HZ mice did show substantial impairments, a $40 \%$ reduction in synaptic transmission in synapses between neocortical neurons and striatal fast spiking interneurons (Miyamoto et al., 2019) and 45\% in synapses between PV interneurons and pyramidal neurons (Chen et al., 2020).

Normal MUNC18-1 expression levels are especially required during the high initial rate of DCV exocytosis, which is $\sim 5$ times higher than in later phases (Fig. 3; Arora et al., 2017; Persoon et al., 2018, 2019; Hoogstraaten et al., 2020). In contrast, Munc18-1 HZ chromaffin cells and synapses showed the largest effects during later phases of release (Toonen et al., 2006a,b; Miyamoto et al., 2019), albeit using different stimulation paradigms. It is tempting to speculate that the MUNC18-1-dependent rate-limiting step in the secretory pathway (probably docking/priming and setting up trans-SNARE-complexes) has already taken place before the onset of stimulation in chromaffin cells and synapses,

neurons. Mann-Whitney $U$ test: ${ }^{*} p<0.05$. $\boldsymbol{F}$, Normalized cumulative representation of the data in $\boldsymbol{A}$. Error bars are SEM. $\boldsymbol{G}$, The Tukey/scatter plot shows the median delay of BDNFpHluorin-labeled DCV exocytosis events relative to the start of each train-stimulation for Munc18-1 WT and HZ neurons. The delay within each train-stimulation is similar between Munc18-1 WT and HZ neurons. In both WT and HZ neurons, the median delay of exocytosis is decreased during the second train-stimulation compared with the first. Kruskal-Wallis with Dunn's correction: ${ }^{* *} p<0.001$, n.s. $=$ non-significant. $\boldsymbol{H}$, The Tukey/scatter plot shows that the total pool of DCVs per cell, revealed by $\mathrm{NH}_{4}$ application, is similar for Munc18-1 WT and HZ neurons. Mann-Whitney U test: ns = non-significant. I, The Tukey/ scatter plot shows that the number of DCV exocytosis events normalized by the total pool (indicated as release fraction) is decreased in Munc18-1 HZ neurons during the first trainstimulation. Mann-Whitney $U$ test: ${ }^{*} p<0.05$. J, The Tukey/scatter plot shows the number of DCV exocytosis events normalized by the total pool (indicated as release fraction) for Munc18-1 WT and HZ neurons during the second train-stimulation. Mann-Whitney $U$ test: n.s. $=$ non-significant. 
while for neuronal DCVs this occurs after the onset. Such a scenario may help to explain why neuronal DCV exocytosis is so much slower than SV exocytosis and why the initial secretion response in synapses and chromaffin cells is hardly affected by reduced MUNC18-1 expression.

In dual train-stimulated neurons (two episodes of $8 \times 50$ APs), NPY-pHluorin and BDNF-pHluorin exocytosis events were accelerated at the onset of the second stimulation compared with the first (Figs. 4, 6). To our knowledge, such an acceleration of neuronal DCV exocytosis has not been reported before. Munc18-1 HZ inactivation did not affect this acceleration (Figs. $4,6)$. Hence, normal MUNC18-1 expression levels are not required for the acceleration of DCV exocytosis during a second train-stimulation. However, neurons with a reduced MUNC18-1 level, but not WT neurons, show potentiation of DCV exocytosis during the second train-stimulation (Figs. 4, 6). Potentiation of DCV exocytosis during dual stimulation has also been observed in (WT) Drosophila neuromuscular junctions, where ER-mediated calcium release elevates neuropeptide release via CaMKII during a second stimulation episode (Shakiryanova et al., 2007). However, mouse neuronal DCV exocytosis is normal in the absence of both $\alpha$ and $\beta$ CaMKII (Moro et al., 2020), suggesting that a possible potentiation mechanism does not depend on CaMKII in mouse neurons.

This study shows that neuronal DCV exocytosis is particularly vulnerable to reduced MUNC18-1 expression levels. This finding may be relevant for STXBP1 syndrome, which is caused by mutations in the human STXBP1 gene (encoding for MUNC18-1) and characterized by developmental delay, intellectual disability, often epilepsy, motor abnormalities and sometimes also autistic traits (Saitsu et al., 2008; Stamberger et al., 2016; Abramov et al., 2020). Haploinsufficiency, because of impaired MUNC18-1/STXBP1 protein stability and consequently reduced cellular levels, is considered to explain the disease in most cases (Guiberson et al., 2018; Kovacevic et al., 2018; Verhage and Sørensen, 2020). Munc18-1 HZ mice recapitulate the major hallmarks of STXBP1 syndrome (Kovacevic et al., 2018; Miyamoto et al., 2019; Chen et al., 2020). Impaired neuropeptide secretion may contribute, in addition to reduced synaptic transmission, to the behavioral and neurodevelopmental phenotypes in Munc18-1 HZ mice and the pathogenesis of STXBP1 syndrome.

\section{References}

Aalto MK, Ronne H, Keränen S (1993) Yeast syntaxins Ssolp and Sso2p belong to a family of related membrane proteins that function in vesicular transport. EMBO J 12:4095-4104.

Abramov D, Guiberson NGL, Burré J (2020) STXBP1 encephalopathies: clinical spectrum, disease mechanisms, and therapeutic strategies. J Neurochem 157:165-178.

André T, Classen J, Brenner P, Betts MJ, Dörr B, Kreye S, Zuidinga B, Meijer M, Russell RB, Verhage M, Söllner TH (2020) The interaction of Munc18-1 helix 11 and 12 with the central region of the VAMP2 SNARE motif is essential for SNARE templating and synaptic transmission. eNeuro 7:ENEURO.0278-20.2020.

Arora S, Saarloos I, Kooistra R, van de Bospoort R, Verhage M, Toonen RF (2017) SNAP-25 gene family members differentially support secretory vesicle fusion. J Cell Sci 130:1877-1889.

Bin NR, Jung CH, Piggott C, Sugita S (2013) Crucial role of the hydrophobic pocket region of Munc18 protein in mast cell degranulation. Proc Natl Acad Sci USA 110:4610-4615.

Borghesani PR, Peyrin JM, Klein R, Rubin J, Carter AR, Schwartz PM, Luster A, Corfas G, Segal RA (2002) BDNF stimulates migration of cerebellar granule cells. Development 129:1435-1442.
Burkhardt P, Hattendorf DA, Weis WI, Fasshauer D (2008) Munc18a controls SNARE assembly through its interaction with the syntaxin N-peptide. EMBO J 27:923-933.

Cao P, Yang X, Südhof TC (2013) Complexin activates exocytosis of distinct secretory vesicles controlled by different synaptotagmins. J Neurosci 33:1714-1727.

Cardenas EI, Gonzalez R, Breaux K, Da Q, Gutierrez BA, Ramos MA, Cardenas RA, Burns AR, Rumbaut RE, Adachi R (2019) Munc18-2, but not Munc18-1 or Munc18-3, regulates platelet exocytosis, hemostasis, and thrombosis. J Biol Chem 294:4784-4792.

Chen BY, Wang X, Wang ZY, Wang YZ, Chen LW, Luo ZJ (2013) Brainderived neurotrophic factor stimulates proliferation and differentiation of neural stem cells, possibly by triggering the $\mathrm{Wnt} / \beta$-catenin signaling pathway. J Neurosci Res 91:30-41.

Chen W, Cai ZL, Chao ES, Chen H, Longley CM, Hao S, Chao HT, Kim JH, Messier JE, Zoghbi HY, Tang J, Swann JW, Xue M (2020) Stxbp1/ Munc18-1 haploinsufficiency impairs inhibition and mediates key neurological features of STXBP1 encephalopathy. Elife 9:e48705.

Cheng PL, Song AH, Wong YH, Wang S, Zhang X, Poo MM (2011) Selfamplifying autocrine actions of BDNF in axon development. Proc Natl Acad Sci USA 108:18430-18435.

Cijsouw T, Weber JP, Broeke JH, Broek JAC, Schut D, Kroon T, Saarloos I, Verhage M, Toonen RF (2014) Munc18-1 redistributes in nerve terminals in an activity- and PKC-dependent manner. J Cell Biol 204:759-775.

Collin C, Vicario-Abejon C, Rubio ME, Wenthold RJ, McKay RDG, Segal M (2001) Neurotrophins act at presynaptic terminals to activate synapses among cultured hippocampal neurons. Eur J Neurosci 13:1273-1282.

Comeras LB, Herzog H, Tasan RO (2019) Neuropeptides at the crossroad of fear and hunger: a special focus on neuropeptide Y. Ann NY Acad Sci 1455:59-80

Côte M, Ménager MM, Burgess A, Mahlaoui N, Picard C, Schaffner C, AlManjomi F, Al-Harbi M, Alangari A, Le Deist F, Gennery AR, Prince N, Cariou A, Nitschke P, Blank U, El-Ghazali G, Ménasché G, Latour S, Fischer A, de Saint Basile G (2009) Munc18-2 deficiency causes familial hemophagocytic lymphohistiocytosis type 5 and impairs cytotoxic granule exocytosis in patient NK cells. J Clin Invest 119:3765-3773.

Cropper EC, Jing J, Vilim FS, Weiss KR (2018) Peptide cotransmitters as dynamic, intrinsic modulators of network activity. Front Neural Circuits $12: 1-7$.

de Wit H, Walter AM, Milosevic I, Gulyás-Kovács A, Riedel D, Sørensen JB, Verhage M (2009) Synaptotagmin-1 docks secretory vesicles to syntaxin1/SNAP-25 acceptor complexes. Cell 138:935-946.

De Wit J, Toonen RF, Verhage M (2009) Matrix-dependent local retention of secretory vesicle cargo in cortical neurons. J Neurosci 29:23-37.

Dulubova I, Khvotchev M, Liu S, Huryeva I, Südhof TC, Rizo J (2007) Munc18-1 binds directly to the neuronal SNARE complex. Proc Natl Acad Sci USA 104:2697-2702.

Farina M, van de Bospoort R, He E, Persoon CM, van Weering JR, Broeke $\mathrm{JH}$, Verhage M, Toonen RF (2015) CAPS-1 promotes fusion competence of stationary dense-core vesicles in presynaptic terminals of mammalian neurons. Elife 4:e05438.

Granseth B, Odermatt B, Royle SJJ, Lagnado L (2006) Clathrin-mediated endocytosis is the dominant mechanism of vesicle retrieval at hippocampal synapses. Neuron 51:773-786.

Guiberson NGL, Pineda A, Abramov D, Kharel P, Carnazza KE, Wragg RT, Dittman JS, Burré J (2018) Mechanism-based rescue of Munc18-1 dysfunction in varied encephalopathies by chemical chaperones. Nat Commun 9:3986.

Gulyás-Kovács A, De Wit H, Milosevic I, Kochubey O, Toonen R, Klingauf J, Verhage M, Sørensen JB (2007) Munc18-1: sequential interactions with the fusion machinery stimulate vesicle docking and priming. J Neurosci 27:8676-8686

Gutierrez BA, Chavez MA, Rodarte AI, Ramos M, Dominguez A, Petrova Y, Davalos AJ, Costa RM, Elizondo R, Tuvim MJ, Dickey BF, Burns AR, Heidelberger R, Adachi R (2018) Munc18-2, but not Munc18-1 or Munc18-3, controls compound and single-vesicle regulated exocytosis in mast cells. J Biol Chem 293:7148-7159.

Hackmann Y, Graham SC, Ehl S, Höning S, Lehmberg K, Aricò M, Owen DJ, Griffiths GM (2013) Syntaxin binding mechanism and disease-causing mutations in Munc18-2. Proc Natl Acad Sci USA 110:E4482-E4491. 
Hamada N, Iwamoto I, Tabata H, Nagata KI (2017) MUNC18-1 gene abnormalities are involved in neurodevelopmental disorders through defective cortical architecture during brain development. Acta Neuropathol Commun 5:92.

Hansel DE, Eipper BA, Ronnett GV (2001) Neuropeptide Y functions as a neuroproliferative factor. Nature 410:940-944.

He E, Wierda K, Van Westen R, Broeke JH, Toonen RF, Cornelisse LN, Verhage M (2017) Munc13-1 and Munc18-1 together prevent NSF-dependent de-priming of synaptic vesicles. Nat Commun 8:15915.

Heeroma JH, Roelandse M, Wierda K, Van Aerde KI, Toonen RFG, Hensbroek RA, Brussaard A, Matus A, Verhage M (2004) Trophic support delays but not prevent cell-intrinsic degeneration of neurons deficient for munc18-1. Eur J Neurosci 20:623-634.

Hoogstraaten RI, Keimpema L, VanToonen RF, Verhage M (2020) Tetanus insensitive VAMP2 differentially restores synaptic and dense core vesicle fusion in tetanus neurotoxin treated neurons. Sci Rep 10:10913.

Jahn R, Scheller RH (2006) SNAREs - engines for membrane fusion. Nat Rev Mol Cell Biol 7:631-643.

Jaramillo AM, Piccotti L, Velasco WV, Delgado ASH, Azzegagh Z, Chung F, Nazeer U, Farooq J, Brenner J, Parker-Thornburg J, Scott BL, Evans CM, Adachi R, Burns AR, Kreda SM, Tuvim MJ, Dickey BF (2019) Different Munc18 proteins mediate baseline and stimulated airway mucin secretion. JCI Insight 4:e124815.

Jiao J, He M, Port SA, Baker RW, Xu Y, Qu H, Xiong Y, Wang Y, Jin H, Eisemann TJ, Hughson FM, Zhang Y (2018) Munc18-1 catalyzes neuronal SNARE assembly by templating SNARE association. Elife 7:e41771.

Kaeser PS, Regehr WG (2014) Molecular mechanisms for synchronous, asynchronous, and spontaneous neurotransmitter release. Annu Rev Physiol 76:333-363.

Kaeser PS, Deng L, Wang Y, Dulubova I, Liu X, Rizo J, Südhof TC (2011) RIM proteins tether $\mathrm{Ca} 2+$ channels to presynaptic active zones via a direct PDZ-domain interaction. Cell 144:282-295.

Kauppi M, Wohlfahrt G, Olkkonen VM (2002) Analysis of the Munc18bsyntaxin binding interface. Use of a mutant Munc18b to dissect the functions of syntaxins 2 and 3. J Biol Chem 277:43973-43979.

Korteweg N, Maia AS, Thompson B, Roubos EW, Burbach JPH, Verhage M (2005) The role of Munc18-1 in docking and exocytosis of peptide hormone vesicles in the anterior pituitary. Biol Cell 97:445-455.

Kovacevic J, Maroteaux G, Schut D, Loos M, Dubey M, Pitsch J, Remmelink E, Koopmans B, Crowley J, Cornelisse LN, Sullivan PF, Schoch S, Toonen RF, Stiedl O, Verhage M (2018) Protein instability, haploinsufficiency, and cortical hyper-excitability underlie STXBP1 encephalopathy. Brain 141:13501374.

Lam PPL, Ohno M, Dolai S, He Y, Qin T, Liang T, Zhu D, Kang Y, Liu Y, Kauppi M, Xie L, Wan WCY, Bin NR, Sugita S, Olkkonen VM, Takahashi N, Kasai H, Gaisano HY (2013) Munc18b is a major mediator of insulin exocytosis in rat pancreatic b-cells. Diabetes 62:2416-2428.

Lee Y, IlKim YG, Pyeon HJ, Ahn JC, Logan S, Orock A, Joo KM, Lörincz A, Deák F (2019) Dysregulation of the SNARE-binding protein Munc18-1 impairs BDNF secretion and synaptic neurotransmission: a novel interventional target to protect the aging brain. Geroscience 41:109-123.

Medina DL, Sciarretta C, Calella AM, Von Bohlen Und Halbach O, Unsicker $\mathrm{K}$, Minichiello L (2004) TrkB regulates neocortex formation through the Shc/PLCgamma-mediated control of neuronal migration. EMBO J 23:3803-3814.

Meijer M, Dörr B, Lammertse HC, Blithikioti C, Weering JR, Toonen RF, Söllner TH, Verhage M (2018) Tyrosine phosphorylation of Munc18-1 inhibits synaptic transmission by preventing SNARE assembly.EMBO J 37:300-320.

Mennerick S, Que J, Benz A, Zorumski CF (1995) Passive and synaptic properties of hippocampal neurons grown in microcultures and in mass cultures. J Neurophysiol 73:320-332.

Miranda M, Morici JF, Zanoni MB, Bekinschtein P (2019) Brain-derived neurotrophic factor: a key molecule for memory in the healthy and the pathological brain. Front Cell Neurosci 13:363.

Misura KM, Scheller RH, Weis WI (2000) Three-dimensional structure of the neuronal-Sec1-syntaxin 1a complex. Nature 404:355-362.

Miyamoto H, Tatsukawa T, Shimohata A, Yamagata T, Suzuki T, Amano K, Mazaki E, Raveau M, Ogiwara I, Oba-Asaka A, Hensch TK, Itohara S, Sakimura K, Kobayashi K, Kobayashi K, Yamakawa K (2019) Impaired cortico-striatal excitatory transmission triggers epilepsy. Nat Commun 10:1917.
Moro A, Woerden GM, VanToonen RF, Verhage M (2020) CaMKII controls neuromodulation via neuropeptide gene expression and axonal targeting of neuropeptide vesicles. PLoS Biol 18:e3000826.

Murthy VN, Sejnowski TJ, Stevens CF (1997) Heterogeneous release properties of visualized individual hippocampal synapses. Neuron 18:599-612.

Novick P, Schekman R (1979) Secretion and cell-surface growth are blocked in a temperature-sensitive mutant of Saccharomyces cerevisiae. Proc Natl Acad Sci USA 76:1858-1862.

Novick P, Field C, Schekman R (1980) Identification of 23 complementation groups required for post-translational events in the yeast secretory pathway. Cell 21:205-221.

Novick P, Ferro S, Schekman R (1981) Order of events in the yeast secretory pathway. Cell 25:461-469.

Oh E, Thurmond DC (2009) Munc18c depletion selectively impairs the sustained phase of insulin release. Diabetes 58:1165-1174.

Oh E, Kalwat MA, Kim MJ, Verhage M, Thurmond DC (2012) Munc18-1 regulates first-phase insulin release by promoting granule docking to multiple syntaxin isoforms. J Biol Chem 287:25821-25833.

Parisotto D, Pfau M, Scheutzow A, Wild K, Mayer MP, Malsam J, Sinning I, Söllner TH (2014) An extended helical conformation in domain 3a of Munc18-1 provides a template for SNARE (soluble N-ethylmaleimidesensitive factor attachment protein receptor) complex assembly. J Biol Chem 289:9639-9650.

Persoon CM, Moro A, Nassal JP, Farina M, Broeke JH, Arora S, Dominguez N, van Weering JR, Toonen RF, Verhage M (2018) Pool size estimations for dense-core vesicles in mammalian CNS neurons. EMBO J 37:e99672.

Persoon CM, Hoogstraaten RI, Nassal JP, van Weering JRT, Kaeser PS, Toonen RF, Verhage M (2019) The RAB3-RIM pathway is essential for the release of neuromodulators. Neuron 104:1065-1080.e12.

Pons-Vizcarra M, Kurps J, Tawfik B, Sørensen JB, van Weering JRT, Verhage M (2019) MUNC18-1 regulates submembrane F-actin network, independently of syntaxin 1 targeting, via hydrophobicity in $\beta$-sheet 10. J Cell Sci 132:234674

Protopopov V, Govindan B, Novick P, Gerst JE (1993) Homologs of the synaptobrevin/VAMP family of synaptic vesicle proteins function on the late secretory pathway in S. cerevisiae. Cell 74:855-861.

Raposinho PD, Broqua P, Pierroz DD, Hayward A, Dumont Y, Quirion R, Junien JL, Aubert ML (1999) Evidence that the inhibition of luteinizing hormone secretion exerted by central administration of neuropeptide $\mathrm{Y}$ (NPY) in the rat is predominantly mediated by the NPY-Y5 receptor subtype. Endocrinology 140:4046-4055.

Rosenmund C, Clements JD, Westbrook GL (1993) Nonuniform probability of glutamate release at a hippocampal synapse. Science 262:754-757.

Saitsu H, Kato M, Mizuguchi T, Hamada K, Osaka H, Tohyama J, Uruno K, Kumada S, Nishiyama K, Nishimura A, Okada I, Yoshimura Y, Hirai SI, Kumada T, Hayasaka K, Fukuda A, Ogata K, Matsumoto N (2008) De novo mutations in the gene encoding STXBP1 (MUNC18-1) cause early infantile epileptic encephalopathy. Nat Genet 40:782-788.

Santos TC, Wierda K, Broeke JH, Toonen RF, Verhage M (2017) Early Golgi abnormalities and neurodegeneration upon loss of presynaptic proteins Munc18-1, syntaxin-1, or SNAP-25. J Neurosci 37:4525-4539.

Schlüter OM, Schmitz F, Jahn R, Rosenmund C, Südhof TC (2004) A complete genetic analysis of neuronal Rab3 function. J Neurosci 24:66296637.

Schlüter OM, Basu J, Südhof TC, Rosenmund C (2006) Rab3 superprimes synaptic vesicles for release: implications for short-term synaptic plasticity. J Neurosci 26:1239-1246.

Schmitz SK, Hjorth JJJ, Joemai RMS, Wijntjes R, Eijgenraam S, de Bruijn P, Georgiou C, de Jong APH, van Ooyen A, Verhage M, Cornelisse LN, Toonen RF, Veldkamp WJH, Veldkamp W (2011) Automated analysis of neuronal morphology, synapse number and synaptic recruitment. J Neurosci Methods 195:185-193.

Schwartz PM, Borghesani PR, Levy RL, Pomeroy SL, Segal RA (1997) Abnormal cerebellar development and foliation in $\operatorname{BDNF}(-/-)$ mice reveals a role for neurotrophins in CNS patterning. Neuron 19:269-281.

Shakiryanova D, Klose MK, Zhou Y, Gu T, Deitcher DL, Atwood HL, Hewes RS, Levitan ES (2007) Presynaptic ryanodine receptor-activated calmodulin kinase II increases vesicle mobility and potentiates neuropeptide release. J Neurosci 27:7799-7806.

Shimojo M, Courchet J, Pieraut S, Torabi-Rander N, Sando R, Polleux F, Maximov A (2015) SNAREs controlling vesicular release of BDNF and development of callosal axons. Cell Rep 11:1054-1066. 
Shinoda Y, Ahmed S, Ramachandran B, Bharat V, Brockelt D, Altas B, Dean C (2014) BDNF enhances spontaneous and activity-dependent neurotransmitter release at excitatory terminals but not at inhibitory terminals in hippocampal neurons. Front Synaptic Neurosci 6:27.

Sitarska E, Xu J, Park S, Liu X, Quade B, Stepien K, Sugita K, Brautigam CA, Sugita S, Rizo J (2017) Autoinhibition of munc18-1 modulates synaptobrevin binding and helps to enable munc13-dependent regulation of membrane fusion. Elife 6:e24278

Stamberger H, Nikanorova M, Willemsen MH, Accorsi P, Angriman M, Baier H, Benkel-Herrenbrueck I, Benoit V, Budetta M, Caliebe A, Cantalupo G, Capovilla G, Casara G, Courage C, Deprez M, Destrée A, Dilena R, Erasmus CE, Fannemel M, Fjær R, et al. (2016) A neurodevelopmental disorder including epilepsy. Neurology 86:954-962.

Südhof TC (2013) Neurotransmitter release: the last millisecond in the life of a synaptic vesicle. Neuron 80:675-690.

Südhof TC, Rothman JE (2009) Membrane fusion: grappling with SNARE and SM proteins. Science 323:474-477.

Südhof TC, Rizo J (2011) Synaptic vesicle exocytosis. Cold Spring HarbPerspect Biol 3:a005637.

Tamori Y, Kawanishi M, Niki T, Shinoda H, Araki S, Okazawa H, Kasuga M (1998) Inhibition of insulin-induced GLUT4 translocation by Munc18c through interaction with syntaxin4 in 3T3-L1 adipocytes. J Biol Chem 273:19740-19746.

Tartaglia N, Du J, Tyler WJ, Neale E, Pozzo-Miller L, Lu B (2001) Protein synthesis-dependent and -independent regulation of hippocampal synapses by brain-derived neurotrophic factor. J Biol Chem 276:37585-37593.

Thurmond DC, Ceresa BP, Okada S, Elmendorf JS, Coker K, Pessin JE (1998) Regulation of insulin-stimulated GLUT4 translocation by Munc18c in 3T3L1 adipocytes. J Biol Chem 273:33876-33883.

Thurmond DC, Kanzaki M, Khan a H, Pessin JE (2000) Munc18c function is required for insulin-stimulated plasma membrane fusion of GLUT4 and insulin-responsive amino peptidase storage vesicles. Mol Cell Biol 20:379-388

Toonen RF, Verhage M (2003) Vesicle trafficking: pleasure and pain from SM genes. Trends Cell Biol 13:177-186.

Toonen RF, Verhage M (2007) Munc18-1 in secretion: lonely Munc joins SNARE team and takes control. Trends Neurosci 30:564-572.

Toonen RF, de Vries KJ, Zalm R, Südhof TC, Verhage M (2005) Munc18-1 stabilizes syntaxin 1 , but is not essential for syntaxin 1 targeting and SNARE complex formation. J Neurochem 93:1393-1400.

Toonen RF, Kochubey O, de Wit H, Gulyas-Kovacs A, Konijnenburg B, Sørensen JB, Klingauf J, Verhage M (2006a) Dissecting docking and tethering of secretory vesicles at the target membrane. EMBO J 25:37253737.

Toonen RF, Wierda K, Sons MS, de Wit H, Cornelisse LN, Brussaard A, Plomp JJ, Verhage M (2006b) Munc18-1 expression levels control synapse recovery by regulating readily releasable pool size. Proc Natl Acad SciUSA 103:18332-18337.

Tschenett A, Singewald N, Carli M, Balducci C, Salchner P, Vezzani A, Herzog H, Sperk G (2003) Reduced anxiety and improved stress coping ability in mice lacking NPY-Y2 receptors. Eur J Neurosci 18:143-148.

Tyler WJ, Pozzo-Miller LD (2001) BDNF enhances quantal neurotransmitter release and increases the number of docked vesicles at the active zones of hippocampal excitatory synapses. J Neurosci 21:4249-4258.

van de Bospoort R, Farina M, Schmitz SK, de Jong A, de Wit H, Verhage M, Toonen RF (2012) Munc13 controls the location and efficiency of densecore vesicle release in neurons. J Cell Biol 199:883-891.

Verhage M, Sørensen JB (2020) SNAREopathies: diversity in mechanisms and symptoms. Neuron 107:22-37.

Verhage M, Maia AS, Plomp JJ, Brussaard AB, Heeroma JH, Vermeer H, Toonen RF, Hammer RE, van den Berg TK, Missler M, Geuze HJ, Südhof TC (2000) Synaptic assembly of the brain in the absence of neurotransmitter secretion. Science 287:864-869.

Voets T, Toonen RF, Brian EC, de Wit H, Moser T, Rettig J, Südhof TC, Neher E, Verhage M (2001) Munc18-1 promotes large dense-core vesicle docking. Neuron 31:581-592.

Wang S, Li Y, Gong J, Ye S, Yang X, Zhang R, Ma C (2019) Munc18 and Munc13 serve as a functional template to orchestrate neuronal SNARE complex assembly. Nat Commun 10:69.

Wierda KDB, Toonen RFG, de Wit H, Brussaard AB, Verhage M (2007) Interdependence of $\mathrm{PKC}$-dependent and $\mathrm{PKC}$-independent pathways for presynaptic plasticity. Neuron 54:275-290.

Yue F, Cheng Y, Breschi A, Vierstra J, Wu W, Ryba T, Sandstrom R, Ma Z, Davis C, Pope BD, Shen Y, Pervouchine DD, Djebali S, Thurman RE, Kaul R, Rynes E, Kirilusha A, Marinov GK, Williams BA, Trout D, et al. (2014) A comparative encyclopedia of DNA elements in the mouse genome. Nature 515:355-364.

Zeisel A, Muñoz-Manchado M, Codeluppi AB, Lönnerberg S, Manno P, La G, Juréus A, Marques S, Munguba H, He L, Betsholtz C, Rolny C, Castelo-Branco G, Hjerling-Leffler J, Linnarsson S (2015) Cell types in the mouse cortex and hippocampus revealed by single-cell RNA-seq. Science 347:1138-1142.

Zhang Q, Liu G, Wu Y, Sha H, Zhang P, Jia J (2011) BDNF promotes EGFinduced proliferation and migration of human fetal neural stem/progenitor cells via the PI3K/Akt pathway. Molecules 16:10146-10156.

Zhou P, Porcionatto M, Pilapil M, Chen Y, Choi Y, Tolias KF, Bikoff JB, Hong EJ, Greenberg ME, Segal RA (2007) Polarized signaling endosomes coordinate BDNF-induced chemotaxis of cerebellar precursors. Neuron 55:53-68.

Zucker RS (1973) Changes in the statistics of transmitter release during facilitation. J Physiol 229:787-810. 